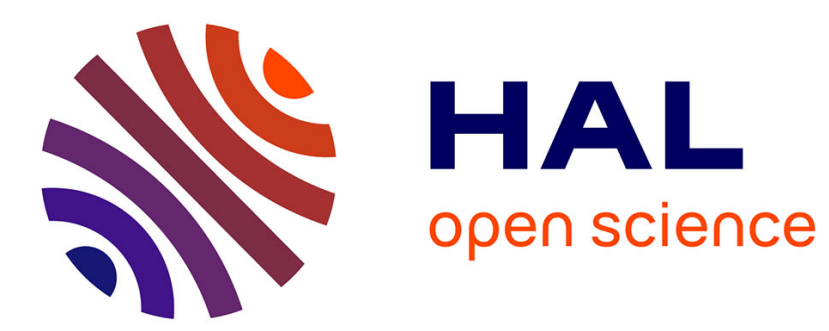

\title{
Macroeconomic Volatility and Trade in OLG Economies
} Antoine Le Riche

\section{To cite this version:}

Antoine Le Riche. Macroeconomic Volatility and Trade in OLG Economies. 2016. halshs-01079773v3

\section{HAL Id: halshs-01079773 \\ https://shs.hal.science/halshs-01079773v3}

Preprint submitted on 24 Apr 2017

HAL is a multi-disciplinary open access archive for the deposit and dissemination of scientific research documents, whether they are published or not. The documents may come from teaching and research institutions in France or abroad, or from public or private research centers.
L'archive ouverte pluridisciplinaire HAL, est destinée au dépôt et à la diffusion de documents scientifiques de niveau recherche, publiés ou non, émanant des établissements d'enseignement et de recherche français ou étrangers, des laboratoires publics ou privés. 


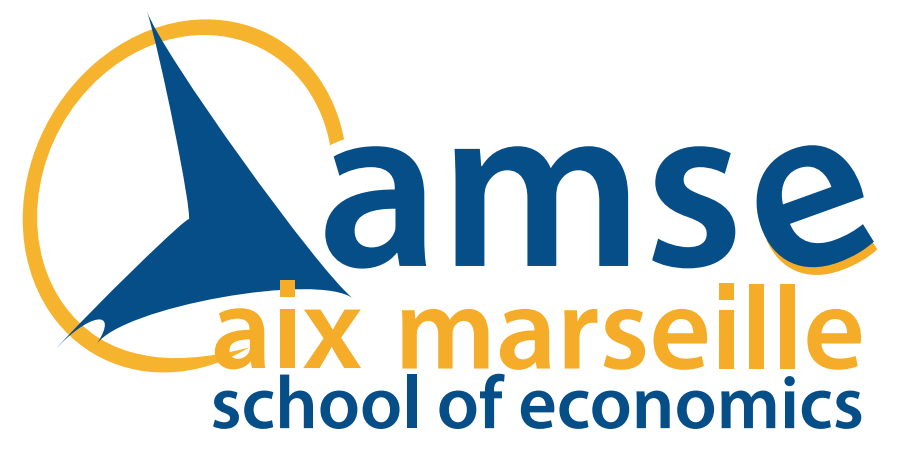

\section{Working Papers / Documents de travail}

Macroeconomic Volatility and Trade in OLG Economies

Antoine Le Riche 


\title{
Macroeconomic Volatility and Trade in OLG economies*
}

\author{
Antoine LE RICHE ${ }^{\dagger}$ \\ Aix-Marseille Univ., CNRS, EHESS, Centrale Marseille, AMSE
}

First version: June 2014; Revised: June 2016

\begin{abstract}
This paper analyzes the effect of free-trade integration on the dynamical properties of economies. We formulate a two-country two-good two-factor overlapping generations model where countries only differ with respect to their discount rate. The main contribution of this paper is to show that opening to international trade may have a destabilizing effect. Especially we prove that, under perfect mobility of labor and capital between countries, sunspot cycles can occur in the trade regime although one country is characterized by saddle-point stability in the autarky regime.
\end{abstract}

Keywords: two-sector OLG model, two-country, local indeterminacy, endogenous fluctuations, dynamic efficiency.

JEL Classification Numbers: C62, E32, F11, F43, O41.

*I would like to warmly thank the Associate Editor and two anonymous referees for their precious suggestions and comments. I wish to thank my advisors, Carine Nourry and Alain Venditti, for having introduced me to the OLG model, for their invaluable advice and continued support together with Sebastian Bervoets, Raouf Boucekkine, Stefano Bosi, Hélène Latzer, Paul Maarek, Francesco Magris, Kazuo Nishimura and Thomas Seegmuller for useful comments and suggestions. This paper benefited from presentations at the "European Doctoral Group in Economics Jamboree", Munich, Germany, September 2012, at the "17th Theories and Methods in Macroeconomics", Lyon, France, March 2013, at the "Overlapping Generations Days", Clermont-Ferrand, France, May 2013, at the Ph.D. seminar of G.R.E.Q.A.M., Marseille, France, June 2013, and at "12th Journées Louis-André Gérard-Varet", Aix-enProvence, France, June 2013. Any remaining errors are our own.

†Addresses for correspondence: A. Le Riche, GREQAM, Aix-Marseille School of Economics, Centre de la Vieille Charité - 2 rue de la Charité, 13236 Marseille cedex 02, France, email: antoine.le-riche@univ-amu.fr. 


\section{Introduction}

The phenomenon of globalization has expanded rapidly in recent decades. One particular feature of globalization is the increasing development of international trade. For example, in the past three decades the value of the share of trade in the gross domestic product has increased by a factor of two for the main OECD countries. ${ }^{1}$ Along with this globalization, the global crisis since 2008 has evidenced that business cycles in countries are increasingly interlinked. Recent empirical studies, using industry-level data to estimate the link between macroeconomic volatility and trade openness, show that countries more exposed to trade are more volatile. ${ }^{2}$ A growing interest has thus emerged for understanding the effect of international trade on the instability of trading economies.

How can trade affect business cycles of trading countries? In this paper, we attempt to address this question by analyzing the co-movement of cycle between countries in a two-good (consumption and investment) two-factor (capital and labor) two-sector model in which the two factors are internationally mobile and countries differ only with respect to their discount rate. In particular, our aim is to study the dynamic behavior of two countries through the occurrence of endogenous fluctuations. A large proportion of the literature considers that endogenous cycles occur through sunspot equilibria and are driven by changes in expectations about fundamentals. This change in expectations is based on the concept of sunspot equilibria defined in Shell (1977). As shown by Woodford (1986), the existence of sunspot equilibria is related to the indeterminacy of the equilibrium under perfect foresight, i.e. the existence of a continuum of equilibrium paths converging towards one steady state from the same initial value of the state variable.

The literature demonstrates that opening to international trade may have different impacts on the stability properties of trading countries. They may be classified into two subsets. In a first one, we find the contributions based on a two-country version of Benhabib and Nishimura (1998) who study the existence of local indeterminacy in a closed two-sector (consumption and investment) infinitely lived agent model with sector-specific externalities and social constant returns with international immobility of factors. ${ }^{3}$ Nishimura and Shimomura (2002) consider a model where countries only differ with respect to their initial factor endowments. They show that international trade has no effect on the stability properties of the two countries. ${ }^{4}$ By contrast, Sim and Ho (2007) consider that the technology are different across countries. ${ }^{5}$ They prove that the world economy is characterized by saddle-point stability even if before trade one country exhibits sunspot fluctuations. Finally, Hu and Mino (2013) consider different trade structure with lending and borrowing, and show that international trade produces endogenous cycles in

\footnotetext{
${ }^{1}$ See OECD Factbook 2010: Economic, Environmental and Social Statistics.

${ }^{2}$ See Kose et al. (2003) and di Giovanni and Levchenko (2009).

${ }^{3}$ They show that sunspot fluctuations arise provided that the investment good sector is more capital intensive than the consumption good section from the social perspective and less capital intensive from the private perspective, and that the elasticity of intertemporal substitution in consumption is large enough.

${ }^{4}$ Iwasa and Nishimura (2014) extend Nishimura and Shimomura (2002) by introducing a consumption capital good. They show that international trade can create sunspot fluctuations in the world economy.

${ }^{5}$ One country is characterized by sector-specific externality and the other country is not.
} 
both countries, even if before trade sunspot cycles do not emerge in the two countries. The second subset of models contains the contributions which deal with international capital mobility and international labor immobility. In a first paper, Nishimura et al. (2010) consider an infinitely-lived agent model with asymmetric technologies across countries and sector-specific externalities. They show that trade creates a contagion of sunspot cycles from one country to another. In a second paper, Nishimura et al. (2014) consider an infinitely-lived agent model with asymmetric technologies across countries and Cobb-Douglas decreasing returns to scale technologies. They analyze the existence of flip bifurcation and deterministic cycles and prove that the destabilizing effect of international trade and international capital mobility arises under certain parameter configurations. In other words, the opening of trade may create persistent endogenous fluctuations at the world level while the closed-economy equilibrium in each country is saddle-point stable.

This literature focuses on the infinitely-lived agent model. In this framework, local indeterminacy necessarily requires the presence of market imperfection such as sector-specific externalities. It implies that any equilibrium is Pareto inefficient. By contrast, local indeterminacy together with dynamic efficiency can arise in overlapping generations (OLG) models without any market imperfection. ${ }^{6}$ In OLG models, Pareto efficiency is associated with under-accumulation of capital stock with respect to the Golden Rule. Reichlin (1986) shows how the co-existence of Pareto efficiency and local indeterminacy in OLG models is an important question in terms of stabilization policies. If sunspot fluctuations occur under dynamic efficiency, a fiscal policy can simultaneously stabilize the economy and reach the Pareto optimal steady state.

Most models that investigate the existence of sunspot fluctuations in the OLG framework consist in closed economies. Among the few exceptions which analyze the effects of international trade on the stability properties of trading countries, two papers deserve particular attention. Aloi and Lloyd-Braga (2010) show that, when countries differ in their labor market regulations, country's sunspot fluctuations can spread throughout the world once trade opens, even if the other country has determinacy under autarky. A second exception is the paper of Aloi et al. (2000) that studies a small-open monetary economy without capital and shows that sunspot fluctuations can exist because households can substitute consumption of non-traded goods for consumption of traded goods. ${ }^{7}$ However, two points have to be made. First, in contrast to the literature with infinitely-lived agent model, they do not consider at a same time the two-sector approach and the effect of international trade on the dynamical properties of economies. Second, these two contributions do not consider the efficiency property of the dynamic equilibrium, as a result they do not mention the issue raised by Reichlin (1986).

The purpose of our paper is to investigate the impact of international trade on the stability properties in Pareto efficient economies. We consider a two-sector two-country OLG version of Drugeon et al. (2010) with one consumption good and one investment good. Our formu-

\footnotetext{
${ }^{6}$ See Nourry and Venditti (2011).

${ }^{7}$ In two-sector two-country model, Bajona and Kehoe (2008) and Mountford (1998) who show the occurrence of local indeterminacy in open economy but they do not consider the effect of international trade on the dynamical properties of economies.
} 
lation differs from Drugeon et al. (2010) in two dimensions. To this end, recall to mind that, Nourry and Venditti (2011) show that local indeterminacy is likely to occur under dynamic efficiency if the sectoral technologies are closed enough to Leontief functions. We thus express our model with a CES technology in the consumption good sector and a Leontief technology in the investment good sector. Second, we suppose decreasing returns to scale on the consumption good sector. This permits us to guarantee a non-degenerate social production function at the world level. We also consider a trade reform consisting in the following hypothesis. First, the two countries are in an autarky regime meaning that goods and factors are traded only on their respective domestic market. Second, both countries are in a trade regime implying that goods are traded on the international market with no transaction cost. In the trade regime, lending and borrowing are not permitted and the factors of production are internationally mobile.

In the autarky regime and the trade regime, we show the existence of endogenous fluctuations together with dynamic efficiency when the consumption good is capital intensive, the value of the elasticity of intertemporal substitution in consumption is intermediate and the degree of returns to scale is high enough. However, the condition on these elasticities and shares to obtain sunspot fluctuations in the autarky and the trade regime differ. Our main focus is to analyze the effect of international trade while the elasticity of intertemporal substitution in consumption is made to vary. For this, we base our analysis on necessary conditions on technologies for local indeterminacy (in the autarky regime and the trade regime) and discuss only the effect of the elasticity of intertemporal substitution in consumption. We are then able to show that opening to trade may create a contagion of sunspot cycles from one country to another.

This paper is organized as follows. Section 2 describes an economy in the autarky regime while Section 3 introduces the analysis of the local dynamics of the closed economy. Section 4 provides the analysis of the two-country model, the pattern of trade and the stability properties. Section 5 shows the existence of the effect of international trade on the dynamical properties in countries with the help of a numerical example. Section 6 contains the concluding remarks and the proofs are gathered in the Appendix.

\section{The autarky model}

We consider a closed economy, which can be north or south, that has two goods (consumption and investment), two factors (capital and labor), and two generations (young and old) in each period. In this Section, we extend the two-sector OLG model of Nourry and Venditti (2011) by considering non increasing returns to scale in the consumption good sector. In the present Section, to simplify the exposition we do not consider any superscripts for the north and the south. However, from Section 4 on, when the two countries are considered at the same time, we will add superscripts $\{N, S\}$ to distinguish them. 


\subsection{Technology}

Consider a competitive economy in which there are two sectors, one representative firm for each sector and each firm producing one good. In this economy there exist two goods: one consumption good produced in quantity $Y_{0, t}$ and one investment good produced in quantity $Y_{t}$. The consumption good is taken as the numéraire. Each sector uses two factors, capital $K_{t}$ and labor $L_{t}$, and both factors are mobile between sectors. Depreciation of capital is complete within one period: ${ }^{8} K_{t+1}=Y_{t}$, where $K_{t+1}$ is the total amount of capital in period $t+1$. The consumption good $Y_{0, t}$ is assumed to be produced with a CES technology and the investment good $Y_{t}$ is assumed to be produced with a Leontief technology

$$
Y_{0, t}=F^{0}\left(K_{t}^{0}, L_{t}^{0}\right)=\Theta\left\{\mu\left(K_{t}^{0}\right)^{-\rho}+(1-\mu)\left(L_{t}^{0}\right)^{-\rho}\right\}^{-\frac{\nu}{\rho}}, Y_{t}=F^{1}\left(K_{t}^{1}, L_{t}^{1}\right)=\min \left\{\frac{K_{t}^{1}}{\eta}, L_{t}^{1}\right\},
$$

where parameter $\mu \in(0,1)$ reflects the capital intensity in production, $\sigma=1 /(1+\rho)>0$ is the sectoral elasticity of capital-labor substitution in the consumption good sector (with $\rho>-1$ ), $v>0$ is the degree of returns to scale in the consumption good sector, $\eta>0$ is the capital intensity in the investment good sector and $\Theta>0$ a normalization constant. We assume non increasing returns to scale in the consumption good sector, i.e., $v \leq 1$.

Labor is normalized to one and given by $L=L_{t}^{0}+L_{t}^{1}=1$, and the capital stock is given by $K_{t}=K_{t}^{0}+K_{t}^{1}$. The optimal allocation of factors between sectors is defined by the social production function $T\left(K_{t}, Y_{t}, L\right)$ :

$$
\begin{array}{r}
T\left(K_{t}, Y_{t}, L\right)=\max _{K_{t}^{j}, L_{t}^{j}, j \in\{0,1\}} Y_{0, t} \\
\text { s.t. } Y_{t} \leq F^{1}\left(K_{t}^{1}, L_{t}^{1}\right), K_{t}^{0}+K_{t}^{1} \leq K_{t}, L_{t}^{0}+L_{t}^{1} \leq L
\end{array}
$$

The social production function is the frontier of the production possibility set and gives the maximal output of the consumption good. Using equation (1) and the resource constraints, $K_{t}=$ $K_{t}^{0}+K_{t}^{1}$ and $L=L_{t}^{0}+L_{t}^{1}$, we define the social production function as:

$$
T\left(K_{t}, Y_{t}, L\right)=\Theta\left[\mu\left(K_{t}-\eta Y_{t}\right)^{-\rho}+(1-\mu)\left(L-Y_{t}\right)^{-\rho}\right]^{-\frac{\nu}{\rho}} .
$$

Let us denote $r_{t}$ the rental rate of capital, $p_{t}$ the price of the investment good and $w_{t}$ the wage rate, all in terms of the price of the consumption good. Using the envelope theorem we obtain the following three relationships: ${ }^{9}$

$$
r\left(K_{t}, Y_{t}, L\right)=T_{1}\left(K_{t}, Y_{t}, L\right), \quad p\left(K_{t}, Y_{t}, L\right)=-T_{2}\left(K_{t}, Y_{t}, L\right), w\left(K_{t}, Y_{t}, L\right)=T_{3}\left(K_{t}, Y_{t}, L\right) .
$$

\footnotetext{
${ }^{8}$ In a two-period OLG model, full depreciation of capital is justified by the fact that one period is about thirty years.

${ }^{9}$ See details in Appendix 7.1.
} 
where $T_{1}=\partial T / \partial K_{t}, T_{2}=\partial T / \partial Y_{t}$ and $T_{3}=\partial T / \partial L$. Using equation (1) and the resource constraints we obtain the relative capital intensity difference $b_{t}$ and the capital intensity in the consumption good sector $a_{t}$ :

$$
b\left(K_{t}, Y_{t}, L\right)=\frac{L_{t}^{1}}{Y_{t}}\left(\frac{K_{t}^{1}}{L_{t}^{1}}-\frac{K_{t}^{0}}{L_{t}^{0}}\right)=\frac{\eta-K_{t}}{L-Y_{t}}, a\left(K_{t}, Y_{t}, L\right)=\frac{K_{t}^{0}}{L_{t}^{0}}=\frac{K_{t}-\eta Y_{t}}{L-Y_{t}}
$$

The sign of $b$ is positive (resp. negative) if and only if the consumption good is labor (resp. capital) intensive. The Stolper-Samuelson effect $(d r / d p, d w / d p)$ and the Rybczynski effect $\left(d Y_{0} / d K, d Y / d K\right)$ are determined respectively by the factor-price frontier and the two fullemployment conditions:

$$
\frac{d r}{d p}=\frac{d Y}{d K}=b^{-1}, \frac{d w}{d p}=\frac{d Y_{0}}{d K}=-a b^{-1} .
$$

Under a labor (resp. capital) intensive consumption good the Stolper-Samuelson effect states that an increase (resp. decrease) of the relative price decreases (resp. increases) the rental rate of capital and raises (resp. decreases) the wage rate whereas the Rybczynski effect specifies that an increase (resp. decrease) of the capital-labor ratio decreases (resp. increases) the production of the consumption good and increases (resp. decreases) the production of the investment good.

Since there may exist decreasing returns to scale in the consumption good sector, firms earn positive profit, $\pi_{c}$. From the first-order conditions, we derive $\pi_{c}\left(K_{t}, Y_{t}, L\right)=T\left(K_{t}, Y_{t}, L\right)(1-v)$. In the following, we suppose that the owner of the firm spend all the profit by purchasing the consumption good, i.e., $\pi_{c}\left(K_{t}, Y_{t}, L_{t}\right)=A_{t}$. We define the GDP function as $T\left(K_{t}, Y_{t}, L_{t}\right)+$ $p\left(K_{t}, Y_{t}, L_{t}\right) Y_{t}=w\left(K_{t}, Y_{t}, L_{t}\right) L_{t}+r\left(K_{t}, Y_{t}, L_{t}\right) K_{t}+\pi_{c}\left(K_{t}, Y_{t}, L_{t}\right)$, we get the share of capital in the economy

$$
s\left(K_{t}, Y_{t}, L\right)=\frac{r\left(K_{t}, Y_{t}, L\right) K_{t}}{T\left(K_{t}, Y_{t}, L\right)+p\left(K_{t}, Y_{t}, L\right) Y_{t}-\pi_{c}\left(K_{t}, Y_{t}, L\right)} \in(0,1)
$$

\subsection{Preferences}

Consider an infinite-horizon discrete time economy that is populated by overlapping generations of agents who live for two periods: they are thus the young and the old. There is no population growth and the population is normalized to one. In the first period, young agents inelastically supply one unit of labor and receive an income $w_{t}$. They assign this income between the saving $\phi_{t}$ and the first period consumption $C_{t}$. In the second period, old agents are retired. The return on saving $R_{t+1} \phi_{t}$ give their income which they spend entirely in the second period consumption $D_{t+1}$. An agent born in period t has preferences defined over consumption of $C_{t}$ and $D_{t+1}$. Intertemporal preferences of agent are described by the following CES utility function:

$$
U\left(C_{t}, D_{t+1}\right)=\left[C_{t}^{\frac{\gamma-1}{\gamma}}+\delta\left(\frac{D_{t+1}}{\Gamma}\right)^{\frac{\gamma-1}{\gamma}}\right]^{\frac{\gamma}{\gamma-1}}
$$


where $\delta$ is the discount factor, $\gamma$ the elasticity of intertemporal substitution in consumption and $\Gamma>0$ a scaling constant parameter. Under perfect foresight and perfect competition, $w_{t}$ and $R_{t+1}$ are considered as given. A young agent who is born at period t solves the following dynamic program

$$
\max _{C_{t}, \phi_{t}, D_{t+1}}\left\{U\left(C_{t}, D_{t+1}\right) \mid C_{t}+\phi_{t}=w_{t}, D_{t+1}=R_{t+1} \phi_{t}\right\} .
$$

Solving the first-order conditions give

$$
C_{t}=\alpha\left(\frac{R_{t+1}}{\Gamma}\right) w_{t}, \quad \alpha\left(\frac{R_{t+1}}{\Gamma}\right)=\frac{1}{1+\delta^{\gamma}\left(\frac{R_{t+1}}{\Gamma}\right)^{\gamma-1}}
$$

where $\alpha\left(R_{t+1} / \Gamma\right) \in(0,1)$ is the propensity to consume of a young agent at period $t$. From the budget constraint (9), we obtain the saving function $\phi_{t}$ :

$$
\phi_{t}=\left[1-\alpha\left(\frac{R_{t+1}}{\Gamma}\right)\right] w_{t}
$$

We assume that the saving is increasing with respect to the gross rate of return $R_{t+1}$.

Assumption $1 \gamma>1$.

This standard Assumption states that the substitution effect following an increase in the gross rate of return $R_{t+1}$ is greater than the income effect.

\subsection{Dynamic equilibrium}

Along a dynamic competitive equilibrium, total savings equal the production of the investment good: $\phi_{t}=p_{t} Y_{t}$. A perfect-foresight competitive equilibrium of an economy in the autarky regime is defined as:

Definition 1 A sequence $\left\{K_{t}, Y_{t}\right\}_{t=0}^{\infty}$, with $K_{t=0}$ given, is a perfect-foresight competitive equilibrium if:

i」 Producers and households are at their optimum: the FOC (4) and (10)-(11) are satisfied and $R_{t+1}=r_{t+1} / p_{t}$

ii] The capital accumulation is determined by $p_{t} Y_{t}=\phi_{t}$ with $Y_{t}=K_{t+1}$;

iii $\rfloor$ The market clearing condition for the consumption good is given by $A_{t}+C_{t}+D_{t}=T\left(K_{t}, Y_{t}, 1\right)$.

We derive from Definition 1 that the dynamics of an economy in the autarky regime is described by the evolution of the capital stock

$$
p\left(K_{t}, K_{t+1}, 1\right) K_{t+1}-w\left(K_{t}, K_{t+1}, 1\right)\left\{1-\alpha\left[\frac{r\left(K_{t+1}, K_{t+2}, 1\right)}{\Gamma p\left(K_{t}, K_{t+1}, 1\right)}\right]\right\}=0
$$


Since $K_{t+1}=Y_{t}$, the set of admissible $\left(K_{t}, K_{t+1}\right)$ is defined as follows

$$
\Omega=\left\{\left(K_{t}, K_{t+1}\right) \in \mathbb{R}_{+}^{2} \mid K_{t} \leq \bar{K}, K_{t+1} \leq F^{1}\left(K_{t}, 1\right)\right\}
$$

where the maximum admissible value of $\bar{K}$ is solution of $K-F^{1}(K, 1)=0$.

\subsection{Steady state and efficiency properties}

A steady state $K_{t}=K_{t+1}=K_{t+2}=K^{*}$ is defined by

$$
p\left(K^{*}, K^{*}, 1\right) K^{*}-w\left(K^{*}, K^{*}, 1\right)\left\{1-\alpha\left[\frac{r\left(K^{*}, K^{*}, 1\right)}{\Gamma p\left(K^{*}, K^{*}, 1\right)}\right]\right\}=0 .
$$

In the following, we consider a set of economic systems parametrized by the elasticity of intertemporal substitution in consumption $\gamma$. We follow the same approach as Drugeon et al. (2010): building on the homogeneity property of the utility function (8), we exploit the scaling parameter $\Gamma$ in order to give conditions for the existence of a normalized steady state (NSS) $K^{*} \in(0, \bar{K})$ which remain unaltered as $\gamma$ is varied. However, we need also to ensure that the value of the propensity to consume of young agents $\alpha(R / \Gamma)$ when evaluated at the NSS does not depend on $\gamma$. This characteristic will be derived by choosing appropriately the value of $\delta$. Let us express $\xi=R / \Gamma$. Under Assumption $1, \alpha(\xi)$ is a monotone decreasing function with $\lim _{\xi \rightarrow 0} \alpha(\xi)=\alpha_{\text {sup }}$, $\lim _{\xi \rightarrow+\infty} \alpha(\xi)=\alpha_{\text {inf }}$ and $\left(\alpha_{\text {inf }}, \alpha_{\text {sup }}\right) \subseteq(0,1)$. We define the inverse function of $\alpha(\xi)$ as

$$
\Phi_{K^{*}}=1-\frac{K^{*} p\left(K^{*}, K^{*}, 1\right)}{w\left(K^{*}, K^{*}, 1\right)}
$$

By adopting a proper value for $K^{*}$, we may find a corresponding value for $\Phi_{K^{*}} \in\left(\alpha_{\text {inf }}, \alpha_{\text {sup }}\right)$. Then, the following Proposition holds

Proposition 1 Under Assumption 1, let $K^{*} \in(0, \bar{K})$ be such that $\Phi_{K^{*}} \in\left(\alpha_{\text {inf }}, \alpha_{\text {sup }}\right)$. Then, there exists a unique value $\Gamma\left(K^{*}\right)>0$ solution of (14) such that $K^{*}$ is a steady state if and only if $\Gamma=\Gamma\left(K^{*}\right)$.

Proof: See Appendix 7.2.

In the remainder of the paper we make the following Assumption so that the existence of a NSS $K^{*}$ is ensured in the autarky regime.

\section{Assumption $2 \Gamma=\Gamma\left(K^{*}\right)$.}

Then, for a given set of parameters describing the consumption and production behavior, we will be able to dissociate the role of $\gamma$ on the local stability of competitive equilibria. 
Let us consider the dynamic efficiency properties of the competitive equilibrium around the NSS $K^{*}$. In two-sector OLG models, the Golden-Rule level of capital $\hat{K}$ is characterized on the basis of the total stationary consumption $A+C+D=T(\hat{K}, \hat{K}, 1)$. Denoting $R^{A}(\hat{K}, \hat{K}, 1)=$ $-T_{1}(\hat{K}, \hat{K}, 1) / T_{2}(\hat{K}, \hat{K}, 1), \hat{K}$ satisfies $R^{A}(\hat{K}, \hat{K}, 1)=1$. Using equation (7) it follows that $w / r K=$ $(1-s) / s$, we derive from (14) that the stationary gross rate of return at the NSS $K^{*}$ is

$$
R^{A}=\frac{s}{(1-\alpha)(1-s)} .
$$

If $R^{A}>1$ (resp. $R^{A}<1$ ), the NSS $K^{*}$ is lower (resp. higher) than the Golden-Rule level, i.e. the economy displays under- (resp. over-) accumulation of capital. Using the Golden-Rule level $R^{A}=1$ and equation (16), we derive, following the same methodology as Drugeon et al. (2010), a condition on the propensity to consume of young agent $\alpha$ to obtain a NSS $K^{*}$ lower than the Golden-Rule level and to ensure the dynamic efficiency of equilibria. Then the following applies:

Lemma 1 Under Assumptions 1-2, let $\underline{\alpha}=(1-2 s) /(1-s)$. An intertemporal competitive equilibrium converging toward the NSS is dynamically efficient if $\alpha \in(\underline{\alpha}, 1)$, and dynamically inefficient if $\alpha \in(0, \underline{\alpha})$.

Lemma 1 states that under-accumulation of capital occurs when labor income of agents is less than capital income, i.e. $s \geqslant 1 / 2$, a young agent does not have enough labor income to save a sufficient amount. Under-accumulation of capital can be attained provided the share of consumption of young agents is high enough, i.e. $\alpha>\underline{\alpha}$. In the remainder of the paper, the following Assumption is made:

Assumption $3 \alpha \in(\underline{\alpha}, 1 / 2), s \in(1 / 3,1 / 2), b<0$.

Assumption 3 states that we consider dynamically efficient paths, that we restrain the share of capital in the economy $s$ in order to get positive value for $\underline{\alpha}$, and that we concentrate on a capital intensive consumption good configuration. ${ }^{10}$ Using national accounting data on the most developed countries, Takahashi et al. (2012) show that the aggregate consumption good sector is more capital intensive than the investment good sector.

\section{Local indeterminacy in the autarky regime}

This Section discusses the existence of endogenous fluctuations under dynamic efficiency derived from changes in expectations about fundamentals. Our model consists in one predetermined variable, the current capital stock, and one forward variable, the capital stock of the next period. Local indeterminacy occurs when there exists a continuum of equilibrium paths converging to

\footnotetext{
${ }^{10}$ Cecchi and Garcia-Peñalosa (2010) show that over the period 1960-2003, OECD countries were characterized by a share of capital between 0.35 and 0.5 .
} 
one steady state from the same initial value of the capital stock whereas local determinacy occurs when there is a unique converging equilibrium path for a given initial capital stock. In our setting, the existence of local indeterminacy occurs if the two characteristic roots associated with the linearization of the dynamical system (12) around the NSS have a modulus less than one. Let us introduce the elasticity of the rental rate of capital

$$
\varepsilon_{r k}=-\frac{T_{11}\left(K^{*}, K^{*}, 1\right) K^{*}}{T_{1}\left(K^{*}, K^{*}, 1\right)} \in(0,+\infty)
$$

To proceed through the analysis of the local stability of the NSS, we linearize the difference equation (12) (see Appendix 7.3.1). We follow the methodology of Grandmont et al. (1998) and study the variation of the trace $\mathscr{T}^{A}(\gamma)$ and the determinant $\mathscr{D}^{A}(\gamma)$ in the $\left(\mathscr{T}^{A}(\gamma), \mathscr{D}^{A}(\gamma)\right)$ plane as one parameter of interest, i.e. $\gamma$, is made to vary continuously in its admissible range. This methodology allows to determine the occurrence of local indeterminacy. When the consumption good is capital intensive, i.e. $b<0$, we obtain:

Proposition 2 Under Assumption 1-3, there exist $\underline{b}<\bar{b}<0, \underline{\varepsilon}_{r k}>0$, and $\gamma^{\mathcal{F}}>\gamma^{\mathcal{T}}>1$ such that for $b \in(\underline{b}, \bar{b})$, and $\varepsilon_{r k}>\underline{\varepsilon}_{r k}$, the following results prevail:

$i\rfloor$ the steady state is locally indeterminate when $\gamma \in\left(\gamma^{\mathcal{T}}, \gamma^{\mathcal{F}}\right)$;

$i i\rfloor$ the steady state is locally determinate when $\gamma \in\left(1, \gamma^{\mathcal{T}}\right) \cup\left(\gamma^{\mathcal{F}},+\infty\right)$.

Proof: See Appendix 7.3.2.

This Proposition extends the result of Nourry and Venditti (2011) with a decreasing returns to scale technology in the consumption good sector. In Proposition $2, \gamma^{\mathcal{T}}$ is generically a transcritical bifurcation ${ }^{11}$ leading to the existence of a second steady state which is locally unstable (resp. saddle-point stable) in a right (resp. left) neighborhood of $\gamma^{\mathcal{T}}$, whereas $\gamma^{\mathcal{F}}$ is generically a flip bifurcation value giving rise to period-two cycles which are locally indeterminate (resp. unstable) in a right (resp. left) neighborhood of $\gamma^{\mathcal{F}}$ (See Figure 1).

The intuition of Proposition 2 is the following.

Suppose that agents expect that the gross rate of return of investment will rise at period $t$. Since the elasticity of intertemporal substitution in consumption is higher than one, i.e., $\gamma>1$, this expectation brings agents to reduce their current consumption and save more. In addition, if $\gamma$ is sufficiently high, i.e. $\gamma>\gamma^{\mathcal{T}}$, there is a large increase in the future consumption. At a same time, agents raise their saving and the capital will rise at period $t+1$. Since the consumption good sector is the most capital intensive sector, it implies through the Rybzcynski effect that there is an increase in the production of the consumption good at period $t+1$. The intertemporal

\footnotetext{
${ }^{11}$ When the bifurcation parameter $\gamma$ crosses a $\gamma^{\mathcal{T}}$, one characteristic roots crosses 1 . We cannot a priori differentiate between the transcritical, the pitchfork or the saddle-node bifurcation from the difference equation (12). Under assumption 2, the existence of the NSS is always ensured and a saddle-node bifurcation cannot occur. Moreover, the pitchfork bifurcation requires non-generic conditions, see Ruelle (1989). In order to simplify the exposition we focus on the generic case and we relate the existence of one characteristic root going through 1 to a transcritical bifurcation.
} 


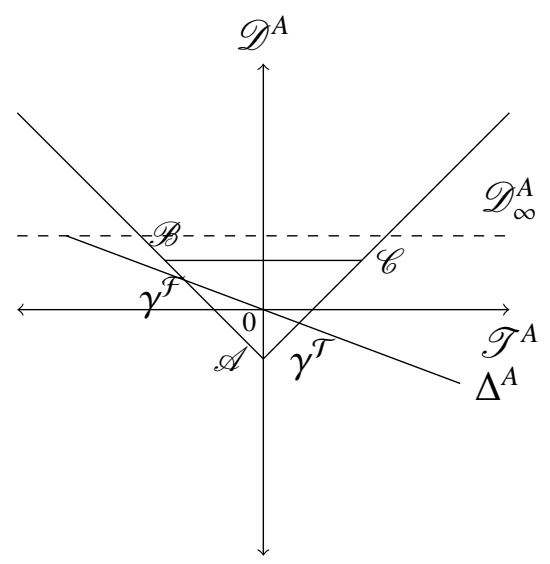

Figure 1: Dynamic efficiency and local indeterminacy in the autarky regime.

substitution effect generates a rise in the future consumption demand and thus the relative price of the investment good $p_{t}$ decreases in order to equilibrate the consumption good market and the investment good market. It implies, through the Stolper-Samuelson effect, that the rate of investment $r_{t}$ increases so that the expectation is self-fulfilling.

On the contrary if $\gamma$ is too small, i.e. $\gamma<\gamma^{\mathcal{T}}$, the intertemporal substitution effect is small and generates a low amount of future consumption demand. Since the consumption good sector is the most capital intensive sector, it follows, through the Rybzcynski effect, that there is an increase in the production of the consumption good at period $t+1$. The relative price of the investment good $p_{t}$ increases in order to equilibrate the consumption good market and the investment good market. This implies through the Stolper-Samuelson effect, that the rate of investment $r_{t}$ decreases so that the expectation is not self-fulfilling.

Finally, if $\gamma$ is too high, i.e. $\gamma>\gamma^{\mathcal{F}}$, agents are willing to save an important amount with a low decrease of their current consumption and an increase of their future consumption. Meanwhile, the capital stock in the next period will rise at an important level. Since the consumption good sector is the most capital intensive one, it implies through the Rybzcynski effect that there is a large increase in the production of the consumption good at time $t+1$. This rise in consumption good production may exceed the increase in future consumption demand. As a result, the expectation is not realized when $\gamma>\gamma^{\mathcal{F}}$.

\section{The two-country model}

In this Section, we consider a two-country model, i.e. the north and the south. First, we present the main assumptions of the model and derive the perfect-foresight equilibrium. Second, we describe the existence of a NSS as well as the efficiency properties. Finally, assuming that the north is the most patient country, we examine the pattern of trade and analyze the local stability. 


\subsection{Assumption of the two-country model}

Consider a world that consists of two countries, referred to $\mathrm{N}$ for the north and $\mathrm{S}$ for the south, which differ only with respect to their discount rate $\delta^{N} \neq \delta^{S}$. In other words, the two countries have different preferences and thus a different capital accumulation path. Capital and labor are mobile across countries such that $r_{t}^{N}=r_{t}^{S}$ and $w_{t}^{N}=w_{t}^{S}$. We assume free-trade, thus the relative price of the investment good is the same in the two countries, i.e. $p_{t}^{N}=p_{t}^{S}$. As the investment good is mobile, there are investment flows across countries. Let us introduce $K_{t}^{W}=K_{t}^{N}+K_{t}^{S}$ the world capital stock at time $t, Y_{t}^{W}=Y_{t}^{N}+Y_{t}^{S}$ the world production of investment good at time $t$ and $L_{t}^{W}=L_{t}^{N}+L_{t}^{S}=2$ the world labor force at time $t$. At each period the balance of trade is at the equilibrium for both countries. For an economy $i \in\{N, S\}$, the balance of trade is given by $\chi_{t}^{i 0}+p_{t} \chi_{t}^{i 1}=0$, where $\chi_{t}^{i 0}$ is the net export of the consumption good in country $i$ at time $t$ and $\chi_{t}^{i 1}$ is the net export of the investment good in country $i$ at time $t$. Since the net export of goods of one country is the net import of the other country, we have $\chi_{t}^{N 0}+\chi_{t}^{S 0}=0, \chi_{t}^{N 1}+\chi_{t}^{S 1}=0$.

We suppose that the consumption good sector is capital intensive, i.e. $b^{i}<0$, as in Assumption 3, and there is no factor intensity reversal. In other words, the capital-labor ratio used in the consumption good sector, i.e. $a_{t}^{i} \equiv K_{t}^{i 0} / L_{t}^{i 0}$, is higher than the capital-labor ratio used in the investment good sector, i.e. $\eta \equiv K_{t}^{i 1} / L_{t}^{i 1}$, at each period (see Figure 2). These two capital-labor ratios are crucial levels which describe the specialization pattern of a country $i \in\{N, S\}$ at time $t$. If $\eta<k_{t}^{i}<a_{t}^{i}$, country $i$ diversifies in the production of the consumption good and the investment good. The range of capital-labor ratio between $\eta$ and $a_{t}^{i}$ is called the cone of diversification. When the north and the south have their capital-labor ratio in the cone of diversification, the free-

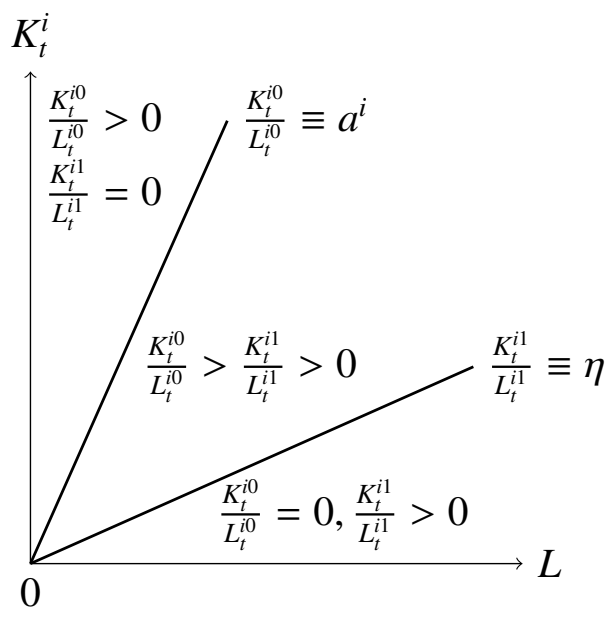

Figure 2: Cone of diversification of country $i \in\{N, S\}$ at time $t$.

trade equilibrium is characterized by an interior equilibrium in which the two countries produce both consumption and investment goods. In our model, the cone of diversification evolves over time since the capital-labor ratio changes overtime. The two countries produce both goods along a free-trade equilibrium if the two countries stay in the corresponding cone of diversification for 
each period $t$. Note that if the two countries are in the cone of diversification at the steady state, the north and the south stay in the cone of diversification in the neighborhood of the steady state. It allows us to provide an analysis of the local dynamics of a world along which each country produces both goods. $^{12}$

\subsection{World dynamic equilibrium}

Trade modifies the restriction that an economy faces. Indeed, an economy in the autarky regime can increase its own capital stock only by producing more investment good but an economy in the trade regime may in addition import the investment good from another economy. For an economy $i \in\{N, S\}$ in the trade regime, the capital accumulation is now given by

$$
p_{t} y_{t}^{i}=p_{t} k_{t+1}^{i}+p_{t} \chi_{t}^{i 1}=\phi_{t}^{i}
$$

For our purpose, we study the dynamic behavior of the two countries at a world level. Such approach allows us to compare the dynamic behavior of an economy in the autarky regime with respect to the dynamic behavior of the world economy. We will thus characterize the world dynamic equilibrium by solving the following optimal allocation of factors problem:

$$
\begin{aligned}
\max _{K_{t}^{i}, Y_{t}^{i}, L_{t}^{i}, i \in\{N, S\}} & \tau\left(K_{t}^{W}, Y_{t}^{W}, 2\right)=T\left(K_{t}^{N}, Y_{t}^{N}, L_{t}^{N}\right)+T\left(K_{t}^{S}, Y_{t}^{S}, L_{t}^{S}\right) \\
\text { s.t. } & K_{t}^{N}+K_{t}^{S} \leq K_{t}^{w} \\
& Y_{t}^{N}+Y_{t}^{S} \leq Y_{t}^{w} \\
& L_{t}^{N}+L_{t}^{S} \leq 2
\end{aligned}
$$

From the envelope theorem we get:

$$
\begin{gathered}
r\left(K_{t}^{W}, Y_{t}^{W}, 2\right)=r\left(K_{t}^{N}, Y_{t}^{N}, L_{t}^{N}\right)=r\left(K_{t}^{S}, Y_{t}^{S}, L_{t}^{S}\right), \\
p\left(K_{t}^{W}, Y_{t}^{W}, 2\right)=p\left(K_{t}^{N}, Y_{t}^{N}, L_{t}^{N}\right)=p\left(K_{t}^{S}, Y_{t}^{S}, L_{t}^{S}\right), \\
w\left(K_{t}^{W}, Y_{t}^{W}, 2\right)=w\left(K_{t}^{N}, Y_{t}^{N}, L_{t}^{N}\right)=w\left(K_{t}^{S}, Y_{t}^{S}, L_{t}^{S}\right) .
\end{gathered}
$$

We define a world perfect-foresight equilibrium as:

Definition 2 A sequence $\left\{K_{t}^{W}, Y_{t}^{W}\right\}_{t=0}^{\infty}$ with $K_{0}^{W}=K_{0}^{N}+K_{0}^{S}$ given, is a world perfect-foresight competitive equilibrium if:

$i\rfloor$ Producers and households are at their optimum: the FOC (4) and (10)-(11) are satisfied and $R_{t+1}^{W}=r_{t+1} / p_{t}$;

\footnotetext{
${ }^{12}$ In Section 4.4 we show that each countries produce both good at the steady state. If at least one country specializes, the dynamics of the world economy examined in the next section is different.
} 
ii] Each period the balance of trade is at the equilibrium for both countries;

iii The capital accumulation is determined by $p_{t}\left(Y_{t}^{N}+Y_{t}^{S}\right)=\phi_{t}^{N}+\phi_{t}^{S}$ with $K_{t+1}^{N}+K_{t+1}^{S}=Y_{t}^{N}+Y_{t}^{S}$; $i v\rfloor$ The market clearing condition for the consumption good is given by $A_{t}^{N}+C_{t}^{N}+D_{t}^{N}+A_{t}^{S}+$ $C_{t}^{S}+D_{t}^{S}=\tau\left(K_{t}^{W}, Y_{t}^{W}, 2\right)$.

We derive from Definition 2 that the dynamics of the world economy is represented by the evolution of the world capital stock

$$
K_{t+1}^{W}-\frac{w\left(K_{t}^{W}, K_{t+1}^{W}, 2\right)\left\{2-\alpha^{N}\left[\frac{r\left(K_{t+1}^{W}, K_{t+2}^{W}, 2\right)}{\Gamma^{N} p\left(K_{t}^{W}, K_{t+1}^{W}, 2\right)}\right]-\alpha^{S}\left[\frac{r\left(K_{t+1}^{W}, K_{t+2}^{W}, 2\right)}{\Gamma^{S} p\left(K_{t}^{W}, K_{t+1}^{W}, 2\right)}\right]\right\}}{p\left(K_{t}^{W}, K_{t+1}^{W}, 2\right)}=0 .
$$

The set of admissible paths is defined as

$$
\Omega^{W}=\left\{\left(K_{t}^{W}, K_{t+1}^{W}\right) \in \mathbb{R}_{+}^{2} \mid K_{t}^{W} \leq \bar{K}^{W}, K_{t+1}^{W} \leq \frac{1}{2}\left[F^{1}\left(K_{t}^{N}, 1\right)+F^{1}\left(K_{t}^{S}, 1\right)\right]\right\}
$$

where the maximal admissible value of $\bar{K}^{W}$ is solution of $K^{W}-\frac{1}{2}\left[F^{1}\left(K^{N}, 1\right)+F^{1}\left(K^{S}, 1\right)\right]=$ 0 . We define the GDP function as $\tau\left(K_{t}^{W}, K_{t+1}^{W}, 2\right)+p\left(K_{t}^{W}, K_{t+1}^{W}, 2\right) K_{t+1}^{W}=w\left(K_{t}^{W}, K_{t+1}^{W}, 2\right)+$ $r\left(K_{t}^{W}, K_{t+1}^{W}, 2\right) K_{t}^{W}+\pi_{c, t}^{N}+\pi_{c, t}^{S}$, we get the share of capital in the world economy

$$
s^{W}\left(K_{t}^{W}, K_{t+1}^{W}, 2\right)=\frac{r\left(K_{t}^{W}, K_{t+1}^{W}, 2\right) K_{t}^{W}}{\tau\left(K_{t}^{W}, K_{t+1}^{W}, 2\right)+p\left(K_{t}^{W}, K_{t+1}^{W}, 2\right) K_{t+1}^{W}-\pi_{c}^{N}-\pi_{c}^{S}} \in(0,1) .
$$

\subsection{World steady state and efficiency properties}

A world steady state $K_{t}^{W}=K_{t+1}^{W}=K_{t+2}^{W}=K^{W *}$ is defined by

$$
K^{W *}-\frac{w\left(K^{W^{*}}, K^{W *}, 2\right)\left\{2-\alpha^{N}\left[\frac{r\left(K^{W *}, K^{W *}, 2\right)}{\Gamma^{N} p\left(K^{W_{*}}, K^{W *}, 2\right)}\right]-\alpha^{S}\left[\frac{r\left(K^{W^{*}, K^{W *}, 2}\right)}{\Gamma^{S} p\left(K^{W^{*}, K^{*}, 2}\right)}\right]\right\}}{p\left(K^{\left.W_{*}, K^{W *}, 2\right)}\right.}=0 .
$$

We follow the same procedure of Section 2.4. Building on the homogeneity property of the utility function, we exploit the scaling parameter $\Gamma^{N}$ in order to give conditions for the existence of a NSS $K^{W *} \in\left(0, \bar{K}^{W}\right)$ in the world economy which remains unaltered as $\gamma$ is made to vary. Let us express $\xi^{N}=R / \Gamma^{N}$. Under gross substitutability, $\alpha^{N}\left(\xi^{N}\right)$ is a monotone decreasing function with $\lim _{\xi^{N} \rightarrow 0} \alpha^{N}\left(\xi^{N}\right)=\alpha_{\text {sup }}^{N}, \lim _{\xi^{N} \rightarrow+\infty} \alpha^{N}\left(\xi^{N}\right)=\alpha_{\text {inf }}^{N}$ and $\left(\alpha_{\text {inf }}^{N}, \alpha_{\text {sup }}^{N}\right) \subseteq(0,1)$. Let us define the inverse function of $\alpha^{N}\left(\xi^{N}\right)$ as:

$$
\Phi_{K^{W *}}=2-\alpha^{S}-\frac{2 K^{W *} p\left(K^{W *}, K^{W *}, 2\right)}{w\left(K^{W^{*}}, K^{W *}, 2\right)} .
$$

By adopting a proper value for $K^{W *}$, we may find a corresponding value for $\Phi_{K^{W *}} \in\left(\alpha_{i n f}^{N}, \alpha_{\text {sup }}^{N}\right)$. Then, the following Proposition holds 
Proposition 3 Under Assumption 1, let $K^{W *} \in\left(0, \bar{K}^{W}\right)$ be such that $\Phi_{K^{W *}} \in\left(\alpha_{i n f}^{N}, \alpha_{\text {sup }}^{N}\right)$. There exists a unique value $\Gamma^{N}\left(K^{W *}\right)>0$ solution of $(24)$ such that $K^{W *}$ is a steady state if and only if $\Gamma^{N}=\Gamma^{N}\left(K^{W *}\right)$.

Proof: See Appendix 7.4.

We introduce the following Assumption to guarantee the existence of a NSS $K^{W *}$ in the trade regime.

\section{Assumption $4 \Gamma^{N}=\Gamma^{N}\left(K^{W *}\right)$.}

As in the autarky regime, the Golden-Rule level of capital $\hat{K}^{W}$ is characterized by the total stationary consumption $A^{N}+C^{N}+D^{N}+A^{S}+C^{S}+D^{S}=\tau\left(\hat{K}^{W}, \hat{K}^{W}, 2\right)$. Denoting $R^{W}\left(\hat{K}^{W}, \hat{K}^{W}, 2\right)=-\tau_{1}\left(\hat{K}^{W}, \hat{K}^{W}, 2\right) / \tau_{2}\left(\hat{K}^{W}, \hat{K}^{W}, 2\right), \hat{K}^{W}$ satisfies $R^{W}\left(\hat{K}^{W}, \hat{K}^{W}, 2\right)=1$. We derive from (24) the propensity to consume of young agent in the world economy $\alpha^{W}$ and the stationary gross rate of return $R^{W}$ at the NSS $K^{W *}$

$$
\alpha^{W}=\frac{1}{2}\left(\alpha^{N}+\alpha^{S}\right), R^{W}=\frac{2 s^{W}}{\left(2-\alpha^{N}-\alpha^{S}\right)\left(1-s^{W}\right)} .
$$

We derive following the same methodology as in the autarky regime a condition on the propensity to consume of young agent $\alpha^{W}$ to obtain a NSS $K^{W *}$ lower than the Golden-Rule level and to ensure the dynamic efficiency of equilibria.

Lemma 2 Under Assumptions 1 and 4, let $\underline{\alpha}^{W}=\left(1-2 s^{W}\right) /\left(1-s^{W}\right)$. An intertemporal dynamic equilibrium converging towards a NSS is dynamically efficient if $\alpha^{W} \in\left(\underline{\alpha}^{W}, 1\right)$, and dynamically inefficient if $\alpha^{W} \in\left(0, \underline{\alpha}^{W}\right)$.

Under free-trade and equation (20), we have $p_{t}=p_{t}^{N}=p_{t}^{S}$ and $r_{t}=r_{t}^{N}=r_{t}^{S}$. This implies that $R=R^{N}=R^{S}$. Thus if the NSS is dynamically efficient in the world economy, the NSS of the north and the south are dynamically efficient.

\subsection{Pattern of trade}

Once we have the world dynamic equilibrium we need to consider the trade pattern. In our two-sector OLG models, during the dynamic transition the pattern of specialization may change overtime since the capital-labor ratio $K_{t}^{i}, i \in\{N, S\}$, evolves. As shown by the following Proposition the two countries produce both goods at the NSS $K^{W *}$ :

Proposition 4 Under Assumptions 1 and 3-4, there exist $\bar{\eta}$ such that for $\eta \in(0, \bar{\eta})$, each country produces both goods at the steady state. 
Proof: See Appendix 7.5.

This Proposition allows to provide an analysis of the stability of the world equilibrium in the neighborhood of the NSS in which both countries produce both goods. We introduce the following Assumption to guarantee the existence of a world economy in which each country produces both goods at the steady state.

Assumption $5 \eta \in(0, \bar{\eta})$.

We suppose in the following that the north and the south differ only with respect to their discount rate $\delta^{N} \neq \delta^{S}$ and that the north has a comparative advantage in the production of the capital intensive good. By using equations (10), (20) and (27), we can show that $\phi_{t}^{N}>\phi_{t}^{S}$. It implies that the north saves more than the south and thus the north is the most patient country. Then the following holds:

Proposition 5 Under Assumptions 1 and 3-5, let consider a world NSS equilibrium in which north and south differ only with respect to their discount rate, i.e., $\delta^{N}>\delta^{S}$. Then the north is the exporter of the capital intensive good while the south is the exporter of the labor intensive good. Proof: See Appendix 7.6.

\subsection{Local indeterminacy in the trade regime}

We now consider the local stability results in the trade regime (see Appendix 7.7.1). In the autarky regime, we study a capital intensive consumption good, then we consider a similar configuration and show the following:

Proposition 6 Under Assumptions 1 and 3-5, there exist $\underline{b}^{S}<\bar{b}^{S}<0, \underline{b}^{N}<\bar{b}^{N}<0, \underline{\varepsilon}_{r k}^{W}>0$, and $\gamma^{W, \mathcal{F}}>\gamma^{W, \mathcal{T}}>1$ such that for $b^{S} \in\left(\underline{b}^{S}, \bar{b}^{S}\right), b^{N} \in\left(\underline{b}^{N}, \bar{b}^{N}\right), \varepsilon_{r k}^{W}>\underline{\varepsilon}_{r k}^{W}$, the following results prevail:

$i\rfloor$ the steady state is locally indeterminate when $\gamma \in\left(\gamma^{W, \mathcal{T}}, \gamma^{W, \mathcal{F}}\right)$;

ii the steady state is locally determinate when $\gamma \in\left(1, \gamma^{W, \mathcal{T}}\right) \cup\left(\gamma^{W, \mathcal{F}},+\infty\right)$.

Proof: See Appendix 7.7.2.

The intuition of Proposition 6 is similar to the intuition of Proposition 2 in the autarky regime. Proposition 6 provides conditions under which local indeterminacy together with dynamic efficiency arise in the world economy. These conditions on elasticities and shares are based on joint restrictions on the parameters of the north and the south. As our result on the occurrence of sunspot fluctuations of an economy in the autarky regime and the world economy differ, international trade may have various effects on the stability properties of each countries. In order to determine the impact of international trade we need to compare the conditions on elasticities and shares of the north and the south in the autarky regime (Proposition 2) with respect to the conditions on elasticities and shares in the trade regime (Proposition 6). 


\section{The effect of international trade}

This Section investigates the impact of opening to international trade on the dynamical properties of the north and the south. In order to determine the impact of international trade we compare the conditions on the bifurcation parameter $\gamma$ of the north and the south in the autarky regime with respect to the bifurcation parameter $\gamma$ in the world economy. The steady state values of all the bifurcations parameters $\gamma$ at the closed and free-trade levels are not the same. Indeed, each bifurcations values depend on different elasticities, shares and thus depend on all parameters of the model. This makes the analytical comparison between the different steady state values of all the bifurcations values not simple and thus we rely on a numerical example.

We now present the numerical conditions such that local indeterminacy holds in the autarky regime for the north and the south. The numerical example is achieved according to the following approach: we choose $\mu, \eta, \rho, v, k^{i}$ and $\gamma$ in their admissible ranges. We then compute the values of $\alpha^{i}, b^{i}, s^{i}, \varepsilon_{r k}^{i}$ and the critical bounds on $b^{i}, \varepsilon_{r k}^{i}$ and $\gamma$. In order to illustrate the result of Proposition 2 , let us consider the following set of parameters:

\begin{tabular}{|c|c|c|c|c|c|c|c|}
\hline$\mu$ & $\eta$ & $\rho$ & $v$ & $K^{N}$ & $K^{S}$ & $\gamma$ & $\Theta$ \\
\hline 0.99996 & 0.1002 & 9 & 0.99 & 0.7501 & 0.7499 & 1.6 & 1 \\
\hline
\end{tabular}

Table 1: Parameters values

Then we derive the conditions for which Proposition 2 is satisfied. Dynamic efficiency holds for $\alpha^{N} \simeq 0.159 \in\left(\underline{\alpha}^{N}, 1 / 2\right)$ and $\alpha^{S} \approx 0.1581 \in\left(\underline{\alpha}^{S}, 1 / 2\right)$ with $\underline{\alpha}^{N} \approx 0.092$ and $\underline{\alpha}^{S} \approx 0.082$. Restrictions on technology in Proposition 2 are satisfied in the north and the south for any $s^{N} \approx$ $0.476 \in(1 / 3,1 / 2), s^{S} \approx 0.478 \in(1 / 3,1 / 2), b^{N} \approx-2.6 \in(-5.292,-1.926), b^{S} \approx-2.598 \in$ $(-5.321,-1.916), \varepsilon_{r k}^{N} \approx 2.618>2.454$ and $\varepsilon_{r k}^{S} \approx 2.609>2.374$. Finally, conditions on $\gamma$ are ensured in the north for any $\gamma \in(1.586,1.768)$ and the south for any $\gamma \in(1.597,1.775)$. The condition on $\gamma$ are represented in Figure 3.

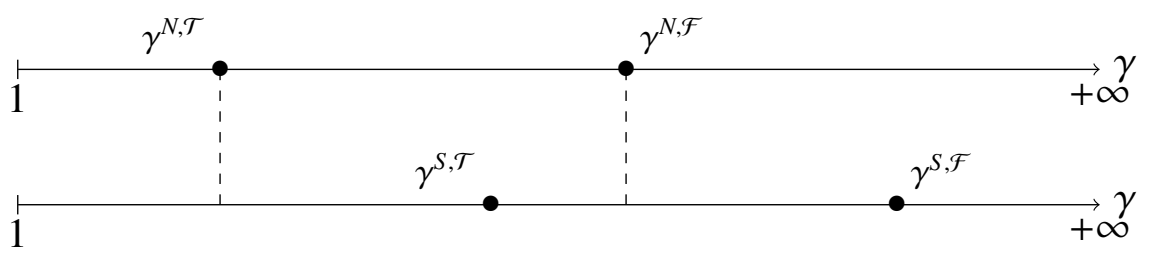

Figure 3: Bifurcation parameters of the north and the south.

Figure 3 shows that the bifurcation parameters for the north and the south are different. In other words, the stability properties of the two countries in the autarky regime are different. For example, when $\gamma \in\left(\gamma^{N, \mathcal{T}}, \gamma^{N, \mathcal{F}}\right)$, the NSS of the north is locally indeterminate while the NSS of the south can either be locally determinate or indeterminate. 
Now, we follow the same approach as in the autarky regime. We consider the same set of parameters as Table 1. As in the autarky regime, the existence of local indeterminacy is based on condition on technology, i.e., $b^{i}$ and $\varepsilon_{r k}^{i}$, and condition on preference, i.e., $\gamma$. The conditions on technology in Proposition 6 are satisfied in the world economy for any $b^{N} \equiv-2.601 \epsilon$ $(-5.297,-2.071), b^{S} \equiv-2.601 \in(-5.317,-2.071)$ and $\varepsilon_{r k}^{W} \equiv 2.607>2.454$. The conditions on preference in Proposition 6 are satisfied in the world economy for any $\gamma \in(1.591,1.769)$. Figure 4 gathers the bifurcation parameters of the north and the south in the autarky regime and the world economy.

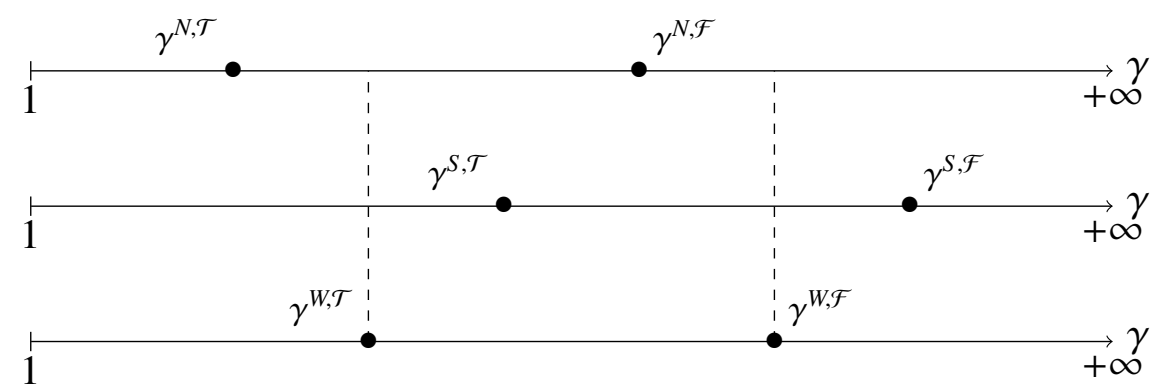

Figure 4: Bifurcation parameters of the north, the south and the world economy.

As mentioned above, the stability properties of the two countries are not the same. Moreover, the bifurcation parameters of the world economy are different from the bifurcation parameters of the two countries. In particular, when $\gamma \in\left(\gamma^{W, \mathcal{T}}, \gamma^{W, \mathcal{F}}\right)$, the NSS of the world economy is locally indeterminate while the NSS of the north and the south can either be locally determinate or indeterminate.

In Figure 5, we represent the different values of $\gamma$ defined in Figure 3 and Figure 4 in only one line. Then, for a given value of $\gamma$, we can deduce the different stability properties of the two countries and thus the effect of international trade.

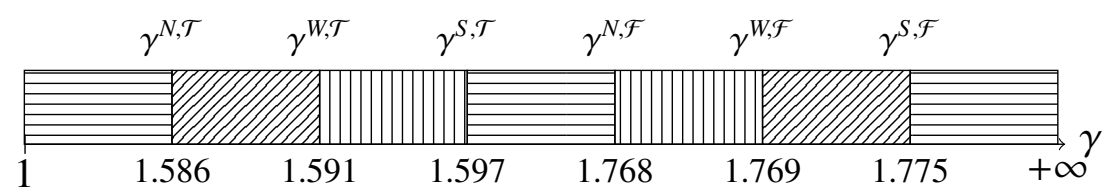
No effect on the dynamical properties of the two countries.
VIIIA Stabilizing effect on the dynamical properties of one country.
|l|l|l| Destabilizing effect on the dynamical properties of one country.

Figure 5: Trade effect on the occurrence of endogenous fluctuations.

We derive, from Figure 5 and the numerical example, the following Proposition which is the main result of the impact of international trade on the dynamical properties of the two countries. 
Proposition 7 Under Assumptions 1 and 3-5, there exists a set of parameters $\left(\eta, \mu, \rho, \nu, \gamma, \gamma^{N, \mathcal{F}}\right.$, $\left.\gamma^{W, \mathcal{F}}\right)$ and allocations $\left(K^{N *}, K^{S *}\right)$ such that the NSS of one country is locally determinate and the NSS of the other country is locally indeterminate in the autarky regime, while local indeterminacy holds for both countries in the trade regime if $\gamma \in\left(\gamma^{W, \mathcal{T}}, \gamma^{S, \mathcal{T}}\right) \cup\left(\gamma^{N, \mathcal{F}}, \gamma^{W, \mathcal{F}}\right)$.

Opening to trade creates a contagion of cycles from one country to another. The intuition of Proposition 7 when $\gamma \in\left(\gamma^{N, \mathcal{F}}, \gamma^{W, \mathcal{F}}\right)$ is the following. Let us suppose that all agents in the world economy anticipate an increase of the gross rate of return.

Let us first consider the expectation of agents in the autarky equilibrium. Since $\gamma>1$, this expectation brings agents in both countries to reduce their current consumption and save more. Through the Rybzcynski effect, there is an increase in the production of the consumption good at period $t+1$.

On the one hand, in the north, agents are most patient of the two country ( $\delta^{N}$ relatively high). In view of the propensity to consume (10), agents are willing to save an important amount with a low decrease of their current consumption and an increase of their future consumption. Meanwhile, the capital stock in the next period will rise at an important level. Since the consumption good sector is the most capital intensive sector, it implies through the Rybzcynski effect that there is a large increase in the production of the consumption good at time $t+1$. This rise in consumption good production may exceed the increase in future consumption demand. As a result, the expectation is not fulfilled for agents in the north.

On the other hand, in the south, the intertemporal substitution effect generates a rise in the future consumption good demand and thus the relative price of investment decreases in order to equilibrate the consumption good market and the investment good market. It implies through the Stolper-Samuelson effect that the rate of investment $r_{t}$ increases so the expectation is fulfilled for the agents in the south.

Let us now consider the free-trade equilibrium.

Since the consumption good is exported from the north to the south, there is less production of the future consumption that remains in the north. Then the consumption good market is equilibrated in the north and as a result, the expectation can be realized as an equilibrium for both countries in the trade regime.

Remark 1 Based on our numerical example and Figure 5, international trade may have other effects. On the one hand, opening to international trade may rule out sunspot fluctuations that exist in the autarky regime. On the other hand, the two countries in the trade regime replicate either local determinacy or local indeterminacy that exist in the autarky regime. 


\section{Concluding remarks}

This paper studied the effect of international trade on the stability properties of trading countries in a two-country two-sector overlapping generations model. The two countries are characterized by CES life cycle utility, CES technology in the consumption good sector and Leontief technology in the investment good sector. Our main result shows that international trade can be a source of macroeconomic volatility. Indeed, by considering a free-trade equilibrium in which one country is a net exporter of the capital intensive consumption good and the other country is a net exporter of the labor intensive investment good, we proved that sunspot fluctuations can occur in the trade regime although one country is characterized by saddle-point stability in the autarky regime.

\section{Appendix}

\subsection{The partial derivatives of $T\left(K_{t}, Y_{t}, L\right)$ in the autarky regime}

We provide preliminary results necessary for the proof. We start by recalling that $T_{g}=$ $T_{g}\left(K_{t}, Y_{t}, L\right)$ and $T_{g h}=T_{g h}\left(K_{t}, Y_{t}, L\right)$, with $g \in\{1,2,3\}$ and $h \in\{1,2\}$. The first partial derivatives of $T\left(K_{t}, Y_{t}, L\right)$ directly follow from computations of (3) and are given by:

Lemma 3 The first partial derivatives of $T\left(K_{t}, Y_{t}, L\right)$ satisfy the following

$$
\begin{gathered}
T_{1}=\Theta \mu \nu\left(K_{t}-\eta Y_{t}\right)^{-(1+\rho)}\left[\mu\left(K_{t}-\eta Y_{t}\right)^{-\rho}+(1-\mu)\left(L-Y_{t}\right)^{-\rho}\right]^{-\frac{v+\rho}{\rho}} ; \\
T_{2}=-T_{1}\left[\eta+\left(\frac{1-\mu}{\mu}\right)\left(\frac{K_{t}-\eta Y_{t}}{L-Y_{t}}\right)^{1+\rho}\right] ; \\
T_{3}=\left(\frac{1-\mu}{\mu}\right)\left(\frac{K_{t}-\eta Y_{t}}{L-Y_{t}}\right)^{1+\rho} T_{1} .
\end{gathered}
$$

Using $a_{t}$ and $b_{t}$ defined in (5) and computations of Lemma 3, we derive the second partial derivatives of $T\left(K_{t}, Y_{t}, L\right)$.

Lemma 4 The second partial derivatives of $T\left(K_{t}, Y_{t}, L\right)$ satisfy the following:

$$
\begin{gathered}
T_{11}=\frac{T_{1}\left[(v-1)-(1+\rho) \frac{T_{3}}{T_{1} a_{t}}\right]}{\left(K_{t}-\eta Y_{t}\right)\left(1+\frac{T_{3}}{T_{1} a_{t}}\right)}, T_{21}=\frac{T_{11}\left[(v-1) \frac{T_{2}}{T_{1}}+(1+\rho) \frac{T_{3} b_{t}}{T_{1} a_{t}}\right]}{v-1-(1+\rho) \frac{T_{3}}{T_{1} a_{t}}} ; \\
T_{22}=-\frac{T_{11}\left[-(v-1)+(1+\rho) \frac{T_{3} b_{t}^{2}}{T_{1} a_{t}}\right]}{v-1-(1+\rho) \frac{T_{3}}{T_{1} a_{t}}} ; T_{31}=\frac{T_{11}(v+\rho) \frac{T_{3}}{T_{1}}}{v-1-(1+\rho) \frac{T_{3}}{T_{1} a_{t}}} ; \\
T_{32}=-\frac{T_{11} \frac{T_{3}}{T_{1}}\left[-(v-1) \frac{T_{2}}{T_{1}}+(1+\rho) b_{t}\right]}{v-1-(1+\rho) \frac{T_{3}}{T_{1} a_{t}}} .
\end{gathered}
$$

Using the fact that $T_{3} / T_{1} a=(1-s) /(1-b) s$, we can rewrite the second partial derivatives of the social production function at the NSS as: 
Lemma 5 At the NSS, the second partial derivatives of $T\left(K^{*}, K^{*}, 1\right)$ satisfy the following:

$$
\begin{gathered}
T_{21}=-\frac{T_{11}(1-s)[(1-v)(1-\alpha)(1-b)+(1+\rho) b]}{(1-v)(1-b) s+(1+\rho)(1-s)}, T_{31}=-\frac{T_{11}(v+\rho)(1-s) a}{(1-v)(1-b) s+(1+\rho)(1-s)} ; \\
T_{22}=\frac{T_{11}\left[(1-v)(1-b) s+(1-s)(1+\rho) b^{2}\right]}{(1-v)(1-b) s+(1+\rho)(1-s)}, T_{32}=\frac{\frac{T_{11} \alpha(1-s)}{s}[(v-1)(1-\alpha)(1-s)+(1+\rho) s b]}{(1-v)(1-b) s+(1+\rho)(1-s)} .
\end{gathered}
$$

\subsection{Proof of Proposition 1}

From the set of admissible paths defined by (13), we have $K^{*} \in(0, \bar{K}) . K^{*}$ is a solution of (14) if

$$
\frac{1}{1+\delta \gamma^{\gamma}\left(\frac{r\left(K^{*}, K^{*}, 1\right)}{\Gamma p\left(K^{*}, K^{*}, 1\right)}\right)^{\gamma-1}}=1-\frac{K^{*} p\left(K^{*}, K^{*}, 1\right)}{w\left(K^{*}, K^{*}, 1\right)} \equiv \Phi_{K^{*}} \in(0,1) .
$$

Let us express $\xi=R / \Gamma$. Under Assumption $1, \alpha(\xi)$ is a monotone decreasing function with $\lim _{\xi \rightarrow 0} \alpha(\xi)=\alpha_{\text {sup }}, \lim _{\xi \rightarrow+\infty} \alpha(\xi)=\alpha_{\text {inf }}$ and $\left(\alpha_{\text {inf }}, \alpha_{\text {sup }}\right) \subseteq(0,1)$. It follows that $\alpha(\xi)$ admits an inverse function defined over $\left(\alpha_{\text {inf }}, \alpha_{\text {sup }}\right)$. Let $K^{*} \in(0, \bar{K})$ be such that $\Phi_{K^{*}} \in\left(\alpha_{\text {inf }}, \alpha_{\text {sup }}\right)$. We then derive that $K^{*}$ is a steady state if and only if $\Gamma=\Gamma\left(K^{*}\right)$. Using Lemma 3, the scaling parameter $\Gamma$ is a unique solution of (14) and is defined by

$$
\Gamma\left(K^{*}\right)=R^{A}\left\{\frac{\delta^{\gamma}\left[(1-s) a\left(1-K^{*}\right)-s \eta(1-b) K^{*}\right]}{K^{*}[s \eta(1-b)+(1-s) a]}\right\}^{\frac{1}{\gamma-1}} .
$$

\subsection{Local stability in the autarky regime}

\subsubsection{Characteristic polynomial in autarky regime}

From (10), the derivative of $\alpha\left(R^{A} / \Gamma\right)$ is given by

$$
\frac{d \alpha\left(R^{A} / \Gamma\right)}{d\left(R^{A} / \Gamma\right)}=-\frac{\alpha(\gamma-1)(1-\alpha) \Gamma}{R^{A}} .
$$

Consider equations (3), (5), (17) and (28) evaluated at the NSS. By totally differentiating equation (12) evaluated at the NSS gives the characteristic polynomial $\mathscr{P}(\lambda)=\lambda^{2}-\lambda \mathscr{T}^{A}(\gamma)+\mathscr{D}^{A}(\gamma)$ with the trace $\mathscr{T}^{A}(\gamma)$ and the determinant $\mathscr{D}^{A}(\gamma)$

$$
\mathscr{T}^{A}(\gamma)=\frac{1+\varepsilon_{r k}\left\{R^{A}\left[\frac{T_{32}(1-\alpha)}{T_{11} k^{*}}+\frac{T_{22}}{T_{11}}\right]+\alpha(\gamma-1)\left[1+\frac{T_{22} R^{A}}{T_{11}}\right]\right\}}{\alpha(\gamma-1)\left(-\frac{T_{21} \varepsilon_{r k}}{T_{11}}\right)}, \mathscr{D}^{A}(\gamma)=\frac{R^{A}\left[1+\alpha(\gamma-1)+(1-\alpha) \frac{T_{31}}{T_{21} K^{*}}\right]}{\alpha(\gamma-1)}
$$

where the first and second partial derivatives of $T\left(K_{t}, Y_{t}, L\right)$ given in Lemma 3 and 4. 


\subsubsection{Proof of Proposition 2}

Under Assumption 2, when $\Gamma=\Gamma\left(K^{*}\right)$, the NSS $K^{*}, \alpha, s$ and $\varepsilon_{r k}$ remains constant as $\gamma$ varies within $(1,+\infty)$. We can analyze the variation of the trace $\mathscr{T}^{A}(\gamma)$ and the determinant $\mathscr{D}^{A}(\gamma)$ in the $\left(\mathscr{T}^{A}(\gamma), \mathscr{D}^{A}(\gamma)\right)$ plane. The relationship between the trace $\mathscr{T}^{A}(\gamma)$ and the determinant $\mathscr{D}^{A}(\gamma)$ is given by a half-line $\Delta^{A}\left(\mathscr{T}^{A}\right)$ which is characterized from the consideration of its extremities. The starting point is the couple $\left(\lim _{\gamma \rightarrow+\infty} \mathscr{T}^{A} \equiv \mathscr{T}_{\infty}^{A}, \lim _{\gamma \rightarrow+\infty} \mathscr{D}^{A} \equiv \mathscr{D}_{\infty}^{A}\right)$, while the end point is the couple $\left(\lim _{\gamma \rightarrow 1} \mathscr{T}^{A} \equiv \mathscr{T}_{1}^{A}, \lim _{\gamma \rightarrow 1} \mathscr{D}^{A} \equiv \mathscr{D}_{1}^{A}\right)$. Solving $\mathscr{T}^{A}$ and $\mathscr{D}^{A}$ with respect to $\alpha(\gamma-1)$ yields to the following linear relationship

$$
\mathscr{D}^{A}=\Delta^{A}\left(\mathscr{T}^{A}\right)=\mathscr{S}^{A} \mathscr{T}^{A}+\mathscr{D}_{\infty}^{A}-\mathscr{S}^{A} \mathscr{T}_{\infty}
$$

where the slope $\mathscr{S}^{A}, \mathscr{D}_{\infty}^{A}$ and $\mathscr{T}_{\infty}^{A}$ are given by

$$
\mathscr{S}^{A}=-\frac{R^{A} \frac{T_{21} K^{*}}{T_{11}} \varepsilon_{r k}\left[1+(1-\alpha) \frac{T_{31}}{T_{21} K^{*}}\right]}{1+\varepsilon_{r k} R^{A}\left[\frac{T_{32}(1-\alpha)}{T_{11} K^{*}}+\frac{T_{22}}{T_{11}}\right]}, \mathscr{D}_{\infty}^{A}=R^{A}, \mathscr{T}_{\infty}^{A}=\frac{(1-v)(1-b)\left(\frac{1+R^{A}}{R^{A}}\right) s+(1+\rho)(1-s)\left(1+b^{2} R^{A}\right)}{(1-s)[(1-v)(1-\alpha)+b(\rho+\alpha+\nu(1-\alpha))]} .
$$

Assume that $b<0, v \leq 1, \alpha \in(\underline{\alpha}, 1 / 2)$ and $s \in(1 / 3,1 / 2)$. Let us first consider the starting point $\left(\mathscr{T}_{\infty}^{A}, \mathscr{D}_{\infty}^{A}\right)$. Under dynamic efficiency, i.e. $\alpha>\underline{\alpha}$, we get from (30) that $\mathscr{D}_{\infty}^{A}>1$. To establish the precise location of the starting point $\left(\mathscr{T}_{\infty}^{A}, \mathscr{D}_{\infty}^{A}\right)$ we need to determine the sign of $\mathscr{T}_{\infty}^{A}, \mathscr{P}_{\infty}^{A}(1)=1-\mathscr{T}_{\infty}^{A}+\mathscr{D}_{\infty}^{A}$ and of $\mathscr{P}_{\infty}^{A}(-1)=1+\mathscr{T}_{\infty}^{A}+\mathscr{D}_{\infty}^{A}$. When $b<\bar{b}$, with $\bar{b}=$ $-(1-\alpha)(1-v) /(v+\rho+(1-v) \alpha)$, we get $\mathscr{T}_{\infty}^{A}<0$. Since $\mathscr{T}_{\infty}^{A}<0$ when $b<\bar{b}$, it follows that $\mathscr{P}_{\infty}^{A}(1)>0$. Using equation (30), we derive that $\mathscr{P}_{\infty}^{A}(-1)$ is given by

$$
\mathscr{P}_{\infty}^{A}(-1)=\frac{2(1-v)(1-b)\left(\frac{1+R^{A}}{R^{A}}\right) s+(1+\rho)(1-s)\left(1+b R^{A}\right)(1+b)}{(1-s)[(1-v)(1-\alpha)+b(\rho+\alpha+\nu(1-\alpha))]} .
$$

Under $b<\bar{b}$, we derive that $\mathscr{P}{ }_{\infty}^{A}(-1)<0$ since $\bar{b}<-1 / R^{A}<-1$. As a result, the starting point is in the left area outside the triangle $\mathscr{A} \mathscr{B} \mathscr{C}$ (see Figure 1). Let us now consider the end point $\left(\mathscr{T}_{1}^{A}, \mathscr{D}_{1}^{A}\right)$. To determine its precise location, it is sufficient to determine whether $\Delta^{A}\left(\mathscr{T}^{A}\right)$ is pointing upward or downward. We thus study the sign of $\mathscr{D}^{A^{\prime}}(\gamma)$

$$
\mathscr{D}^{A^{\prime}}(\gamma)=-\frac{R^{A}(1+\rho)[1-\alpha+b \alpha]}{[(1-v)(1-\alpha)+b(\rho+\alpha+\nu(1-\alpha))] \alpha(\gamma-1)^{2}} .
$$

Under $b \in(\underline{b}, \bar{b})$, with $\underline{b}=-(1-\alpha) / \alpha$, we get $\mathscr{D}^{A^{\prime}}(\gamma)>0$ and thus $\Delta^{A}\left(\mathscr{T}^{A}\right)$ is pointing downward. Therefore when $b \in(\underline{b}, \bar{b})$, the only possibility to get local indeterminacy is that $\Delta^{A}\left(\mathscr{T}^{A}\right)$ crosses the interior of the segment $\mathscr{A} \mathscr{C}$, as depicted in Figure 1. It requires that $\mathscr{T}^{A}>0$ when $\mathscr{D}^{A}=-1$. From (29) solving $\mathscr{D}^{A}=-1$ and using Lemma 5 yields to

$$
\alpha(\gamma-1)=-\frac{R^{A}(1+\rho)(\alpha b+1-\alpha)}{\left(1+R^{A}\right)[(1-\nu)(1-\alpha)(1-b)+(1+\rho) b]} .
$$

which holds if $b \in(\underline{b}, \bar{b})$. Substituting $\mathscr{D}^{A}=-1$ in $\mathscr{T}^{A}$, defined in (29), gives

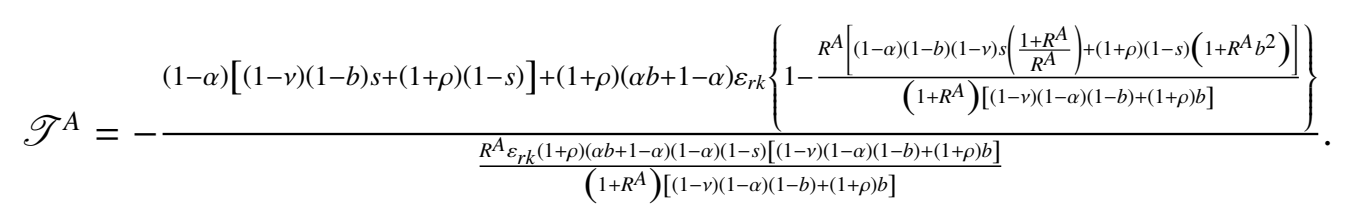


We get that $\mathscr{T}^{A}>0$ when $\mathscr{D}^{A}=-1$ if $\alpha \in(\underline{\alpha}, 1 / 2), s \in(1 / 3,1 / 2), b \in(\underline{b}, \bar{b})$ and $\varepsilon_{r k}>\underline{\varepsilon}_{r k}$. The bound $\underline{\varepsilon}_{r k}$ is defined as

$$
\underline{\varepsilon}_{r k}=\frac{\left(1+R^{A}\right)[(1-\alpha)(1-v)(1-b)+(1+\rho) b][(1-v)(1-b) s+(1+\rho)(1-s)]}{R^{A}(1+\rho)(1-b)^{2}(\alpha b+1-\alpha)[(v-1)[(1-s)(1-\alpha)-s]+(1+\rho)(1+b) s]} .
$$

The bifurcation values $\gamma^{A, \mathcal{T}}$ and $\gamma^{A, \mathcal{F}}$ are, respectively, defined as the solutions of $\mathscr{P}^{A}(1)=$ $1-\mathscr{T}^{A}+\mathscr{D}^{A}=0$ and $\mathscr{P}^{A}(-1)=1+\mathscr{T}^{A}+\mathscr{D}^{A}=0$, and given by

$$
\begin{gathered}
\gamma^{A, \mathcal{T}}=1-\frac{1+\frac{\varepsilon_{r k} R^{A}}{v-1-(1+\rho) \frac{T_{3}}{T_{1} a}}\left[(v-1)\left(1-\left(\frac{1}{R^{A}}\right)^{2}\right)+(1+\rho)(1-b)\left(\frac{1}{R^{A}}+\frac{T_{3} b}{T_{1} a}\right)\right]}{\frac{\varepsilon_{r k^{\alpha}}}{v-1-(1+\rho) \frac{T_{3}}{T_{1} a}}\left[(v-1)\left(R^{A}-\frac{1}{R^{A}}\right)-(1+\rho)(1-b)\left(1-b R^{A}\right) \frac{T_{3} b}{T_{1} a}\right]}, \\
\gamma^{A, \mathcal{F}}=1+\frac{-1+\frac{\varepsilon_{r k} R^{A}}{v-1-(1+\rho) \frac{T_{3}}{T_{1}^{a}}}\left[(v-1)\left(1-\left(\frac{1}{R^{A}}\right)^{2}\right)+(1+\rho)(1-b)\left(\frac{1}{R^{A}}+\frac{T_{3} b}{T_{1} a}\right)\right]}{\frac{\varepsilon_{r k} \alpha}{v-1-(1+\rho) \frac{T_{3}}{T_{1} a}}\left[(v-1)\left(1+R^{A}\right)\left(1+\frac{1}{R^{A}}\right)-(1+\rho)(1+b)\left(1-b R^{A}\right) \frac{T_{3} b}{T_{1} a}\right]} .
\end{gathered}
$$

Results follow.

\subsection{Proof of Proposition 3}

From the set of admissible paths defined by (22), we have $K^{W *} \in\left(0, \bar{K}^{W}\right) . K^{W *}$ is a solution of (21) if

$$
\frac{1}{1+\left(\delta^{N}\right)^{\gamma}\left(\frac{r\left(K^{W *}, K^{W *}, 1\right.}{\Gamma^{N} p\left(K^{\left.W_{*}^{*}, K^{W *}, 1\right)}\right)}\right)^{\gamma-1}}=2-\alpha^{S}-\frac{2 K^{W_{*}^{*}} p\left(K^{W^{*}}, K^{W *}, 1\right)}{w\left(K^{\left.W_{*}, K^{W *}, 1\right)}\right.} \equiv \Phi_{K^{W *}} \in(0,1) .
$$

Let us express $\xi^{N}=R^{W} / \Gamma^{N}$. Under Assumption $1, \alpha^{N}\left(\xi^{N}\right)$ is a monotone decreasing function with $\lim _{\xi \rightarrow 0} \alpha^{N}\left(\xi^{N}\right)=\alpha_{\text {sup }}^{N}, \lim _{\xi \rightarrow+\infty} \alpha^{N}\left(\xi^{N}\right)=\alpha_{\text {inf }}^{N}$ and $\left(\alpha_{\text {inf }}^{N}, \alpha_{\text {sup }}^{N}\right) \subseteq(0,1)$. It follows that $\alpha^{N}\left(\xi^{N}\right)$ admits an inverse function defined over $\left(\alpha_{\text {inf }}^{N}, \alpha_{\text {sup }}^{N}\right)$. Let $K^{W *} \in\left(0, \bar{K}^{W}\right)$ be such that $\Phi_{K^{W *}} \in$ $\left(\alpha_{\text {inf }}^{N}, \alpha_{\text {sup }}^{N}\right)$. We then derive that $K^{W *}$ is a steady state if and only if $\Gamma^{N}=\Gamma^{N}\left(K^{W *}\right)$ with $\Gamma^{N}\left(K^{W *}\right)$ is defined by

$$
\Gamma^{N}\left(K^{W *}\right)=R^{W}\left\{\frac{\left(\delta^{N}\right)^{\gamma}\left[\left(1-s^{N}\right) a^{N}\left(1-K^{W *}-K^{N *}\right)-s^{N} \eta\left(1-b^{N}\right)\left(K^{W *}+K^{N *}\right)\right]}{\left(K^{W *}+K^{N *}\right)\left[s^{N} \eta\left(1-b^{N}\right)+\left(1-s^{N}\right) a^{N}\right]}\right\}^{\frac{1}{\gamma-1}}
$$

\subsection{Proof of Proposition 4}

North and south produce both goods if the capital intensity in the consumption good sector $a^{i}$, $i \in\{N, S\}$, and in the investment good sector $\eta$ are positive. Since we assumed that $\eta>0$, the only remain task is to look at $a^{i}$. Recall to mind that, when taking into account labor mobility 
and capital mobility, the north can export/import capital such that $K^{N *}$ corresponds to capital produce in the north and to export/import of capital from the south. Conversely, the north can export/import labor such that $L^{N *}$ corresponds to the labor in the north and to export/import of labor from the south. A similar reasoning can be applied for the south. It follows, by direct inspection of (5), that $a^{N}$ and $a^{S}$ are positive if and only if $\eta<\bar{\eta} \equiv \min \left\{\frac{K^{N *}}{Y^{N *}}, \frac{K^{S *}}{Y^{S *}}\right\}$.

\subsection{Proof of Proposition 5}

Using equations (10) and (20), $\alpha^{S}>\alpha^{N}$ if and only if $\left(\delta^{N}\right)^{\gamma}\left(\Gamma^{N}\right)^{1-\gamma}>\left(\delta^{S}\right)^{\gamma}\left(\Gamma^{S}\right)^{1-\gamma}$. By Replacing $\Gamma^{N}$ and $\Gamma^{S}$, defined in equation (27), we obtain that $K^{N *}>K^{S *}$ and $\phi^{N}>\phi^{S}$, meaning that the north is the most patient country. Let express $K^{S *}$ and $Y^{S *}$ in terms of $K^{N *}$ and $Y^{N *}$ so that:

$$
K^{N *}=K^{S *}+d K^{S}, Y^{N *}=Y^{S *}+d Y^{S}, d K^{S}, d Y^{S}>0
$$

From Definition 2, the world market condition for investment good at the NSS is

$$
K^{N *}+K^{S *}=Y^{N *}+Y^{S *} .
$$

Using equation (35), we get the following relationships

$$
2 K^{N *}-d K^{N}=2 Y^{N *}-d Y^{N}, 2 K^{S *}+d K^{S}=2 Y^{S *}+d Y^{S}
$$

From the two full-employment conditions we obtain: $d Y^{i *} / d K^{i *}=b^{i}$, where $b^{i}$ is defined in equation (5). Then equation (36) can be express as

$$
K^{N *}-Y^{N *}=-\frac{1-b^{N}}{2 b^{N}} d K^{N}, K^{S *}-Y^{S *}=\frac{1-b^{S}}{2 b^{S}} d K^{S} .
$$

Let $\eta \in(0,1)$, from equation (5) evaluated at the NSS, we derive $a^{i}>0$ and $b^{i}<1$. It implies that $K^{S *} \gtrless Y^{S *}$ and $K^{N *} \lessgtr Y^{N *}$ if and only if $b^{i} \gtrless 0$. It follows that, if $b^{i} \in(0,1)$, the north exports the capital intensive investment good and the south exports the labor intensive consumption good and if $b^{i}<0$ the north exports the capital intensive consumption good and the south exports the labor intensive investment good.

\subsection{Local stability in the trade regime}

\subsubsection{Characteristic polynomial in trade regime}

In order to simplify the exposition, we denote

$$
\begin{gathered}
\tau\left(K^{W}, Y^{W}, 2\right)=T\left(K^{N}, Y^{N}, L^{N}\right)+T\left(K^{S}, Y^{S}, L^{S}\right) \\
\tau_{j h}=\tau_{j h}\left(K^{W}, Y^{W}\right), j \in\{1,2,3\}, h \in\{1,2\} ;{ }^{13}
\end{gathered}
$$

\footnotetext{
${ }^{13}$ Where $\tau_{11}=\partial \tau^{2} / \partial^{2} K^{W}, \tau_{12}=\tau_{21}=\partial \tau^{2} / \partial K^{W} \partial Y^{W}, \tau_{22}=\partial \tau^{2} / \partial^{2} Y^{W}, \tau_{31}=\partial \tau^{2} / \partial K^{W} \partial L^{W}$ and $\tau_{32}=$ $\partial \tau^{2} / \partial L^{W} \partial Y^{W}$.
} 


$$
\left|H^{i}\right|=\left|H^{i}\left(K_{t}^{i}, Y_{t}^{i}\right)\right|, i \in\{N, S\} .
$$

In order to obtain a tractable formulation of the characteristic polynomial, we have to define the second partial derivatives of the world social production function $\tau\left(K_{t}^{W}, Y_{t}^{W}, 2\right)$. From Lemma 7 in Nishimura and Yano (1993), the second partial derivatives of the social production function are given by

Lemma 6 Along a free-trade equilibrium, the second partial derivatives of $\tau\left(K_{t}^{W}, Y_{t}^{W}, 2\right)$ satisfy the following:

$$
\begin{gathered}
\tau_{11}=\frac{1}{\Xi}\left[T_{11}^{N}\left|H^{S}\right|+T_{11}^{S}\left|H^{N}\right|\right], \tau_{12}=\frac{1}{\Xi}\left[T_{12}^{N}\left|H^{S}\right|+T_{12}^{S}\left|H^{N}\right|\right] \\
\tau_{22}=\frac{1}{\Xi}\left[T_{22}^{N}\left|H^{S}\right|+T_{22}^{S}\left|H^{N}\right|\right], \tau_{31}=\frac{1}{\Xi}\left[T_{31}^{N}\left|H^{S}\right|+T_{31}^{S}\left|H^{N}\right|\right] \\
\tau_{32}=\frac{1}{\Xi}\left[T_{32}^{N}\left|H^{S}\right|+T_{32}^{S}\left|H^{N}\right|\right]
\end{gathered}
$$

where

$$
\begin{gathered}
\left|H^{i}\right|=T_{11}^{i} T_{22}^{i}-\left(T_{21}^{i}\right)^{2}>0 \\
\Xi=\left[T_{11}^{N}+T_{11}^{S}\right] \times\left[T_{22}^{N}+T_{22}^{S}\right]-\left[T_{12}^{N}+T_{12}^{S}\right]^{2}>0
\end{gathered}
$$

Letting

$$
\Phi^{N}=\frac{1-\alpha^{N}}{2-\alpha^{N}-\alpha^{S}}, \quad \Phi^{S}=\frac{1-\alpha^{S}}{2-\alpha^{N}-\alpha^{S}},
$$

consider the derivatives of $\alpha^{i}$ with respect to $\left(R^{W} / \Gamma^{i}\right)$ given in equation (28) and $\varepsilon_{r k}^{W}=$ $-\tau_{11} K^{W *} / \tau_{1}$. Totally differentiate equation (21) evaluated at the NSS gives the characteristic $\mathscr{P}^{W}\left(\lambda^{W}\right)=\left(\lambda^{W}\right)^{2}-\lambda^{W} \mathscr{T}^{W}(\gamma)+\mathscr{D}^{W}(\gamma)$ with $\mathscr{T}^{W}(\gamma)$ is the trace and $\mathscr{D}^{W}(\gamma)$ is the determinant and are given by

$$
\begin{gathered}
\mathscr{T}^{W}(\gamma)=\frac{1+\varepsilon_{r k}^{W}\left\{R^{W}\left[\frac{\tau_{32}\left(2-\alpha^{N}-\alpha^{S}\right)}{\tau_{11} K^{W *}}+\frac{\tau_{22}}{\tau_{11}}\right]+\left(\alpha^{N} \Phi^{N}+\alpha^{S} \Phi^{S}\right)(\gamma-1)\left[1+\frac{\tau_{22} R^{W}}{\tau_{11}}\right]\right\}}{\left(\alpha^{N} \Phi^{N}+\alpha^{S} \Phi^{S}\right)(\gamma-1)\left(-\frac{\tau_{21} \varepsilon_{r k}^{W}}{\tau_{11}}\right)}, \\
\mathscr{D}^{W}(\gamma)=\frac{R^{W}\left[1+\left(\alpha^{N} \Phi^{N}+\alpha^{S} \Phi^{S}\right)(\gamma-1)+\frac{\tau_{31}\left(2-\alpha^{N}-\alpha^{S}\right)}{\tau_{21} K^{W *}}\right]}{\left(\alpha^{N} \Phi^{N}+\alpha^{S} \Phi^{S}\right)(\gamma-1)},
\end{gathered}
$$

where the second partial derivatives of $\tau\left(K^{W}, Y^{W}, 2\right)$ are defined in Lemma 6.

\subsubsection{Proof of Proposition 6}

The result of this Proposition is obtained using the geometrical method developed in Grandmont et al. (1998) which allows to determine the occurrence of local indeterminacy in terms of a unique parameter. Under Assumption 4, the NSS $K^{W *}, \alpha^{N}, \alpha^{S}, s^{N}, s^{S}$ and $\varepsilon_{r k}$ remain 
constant as $\gamma$ varies continuously within $(1,+\infty)$. We can thus analyze the variation of the trace $\mathscr{T}^{W}(\gamma)$ and the determinant $\mathscr{D}^{W}(\gamma)$ in the $\left(\mathscr{T}^{W}(\gamma), \mathscr{D}^{W}(\gamma)\right)$ plane. The relationship between the trace $\mathscr{T}^{W}(\gamma)$ and the determinant $\mathscr{D}^{W}(\gamma)$ is given by a half-line $\Delta^{W}\left(\mathscr{T}^{W}\right)$ which is characterized from the consideration of its extremities. The starting point is the couple $\left(\lim _{\gamma \rightarrow+\infty} \mathscr{T}^{W} \equiv \mathscr{T}_{\infty}^{W}, \lim _{\gamma \rightarrow+\infty} \mathscr{D}^{W} \equiv \mathscr{D}_{\infty}^{W}\right)$, while the end point is the couple $\left(\lim _{\gamma \rightarrow 1} \mathscr{T}^{W} \equiv \mathscr{T}_{1}^{W}\right.$ , $\left.\lim _{\gamma \rightarrow 1} \mathscr{D}^{W} \equiv \mathscr{D}_{1}^{W}\right)$. Solving $\mathscr{T}^{W}$ and $\mathscr{D}^{W}$ with respect to $\left(\alpha^{N} \Phi^{N}+\alpha^{S} \Phi^{S}\right)(\gamma-1)$ yields to the following linear relationship

$$
\mathscr{D}^{W}=\Delta\left(\mathscr{T}^{W}\right)=\mathscr{S}^{W} \mathscr{T}^{W}+\mathscr{D}_{\infty}^{W}-\mathscr{S}^{W} \mathscr{T}_{\infty}^{W}
$$

where the slope $\mathscr{S}^{W}, \mathscr{D}_{\infty}^{W}$ and $\mathscr{T}_{\infty}^{W}$ are given

$$
\mathscr{S}^{W}=-\frac{R^{W} \frac{\tau_{21} K^{W}}{\tau_{11}} \varepsilon_{r k}^{W}\left[1+\left(2-\alpha^{N}-\alpha^{S}\right) \frac{\tau_{31}}{\tau_{21} K^{W}}\right]}{1+\varepsilon_{r k}^{W} R^{W}\left[\frac{\tau_{32}\left(2-\alpha^{N}-\alpha^{S}\right)}{\tau_{11} K^{W}}+\frac{\tau_{22}}{\tau_{11}}\right]}, \mathscr{D}_{\infty}^{W}=R^{W}, \mathscr{T}_{\infty}^{W}=-\frac{1+\frac{\tau_{22}^{W} R^{W}}{\tau_{11}^{W}}}{\frac{\tau_{21}^{W}}{\tau_{11}^{W}}} .
$$

Assume that $b^{N}<0, b^{S}<0, v \leq 1, \alpha^{N} \in\left(\underline{\alpha}^{N}, 1 / 2\right), \alpha^{S} \in\left(\underline{\alpha}^{S}, 1 / 2\right) s^{N} \in(1 / 3,1 / 2)$ and $s^{S} \in(1 / 3,1 / 2)$. Let us first consider the starting point $\left(\mathscr{T}_{\infty}^{W}, \mathscr{D}_{\infty}^{W}\right)$. Under dynamic efficiency we get from (39) that $\mathscr{D}_{\infty}^{W}>1$. To establish the precise location of the starting point $\left(\mathscr{T}_{\infty}^{W}, \mathscr{D}_{\infty}^{W}\right)$ we need to determine the sign of $\mathscr{T}_{\infty}^{W}, \mathscr{P}_{\infty}^{W}(1)=1-\mathscr{T}_{\infty}^{W}+\mathscr{D}_{\infty}^{W}$ and of $\mathscr{P}_{\infty}^{W}(-1)=1+\mathscr{T}_{\infty}^{W}+\mathscr{D}_{\infty}^{W}$. Using Lemma 5 and Lemma 6, we get

$$
\mathscr{T}_{\infty}^{W}=\frac{\left[\frac{(1-v)\left(1-b^{N}\right)\left(1+R^{W}\right) s^{N}+(1+\rho)\left(1-s^{N}\right)\left(1+R^{W}\left(b^{N}\right)^{2}\right)}{(1-\gamma)\left(1-b^{N}\right) s^{N}+(1+\rho)\left(1-s^{N}\right)}\right] T_{11}^{N}\left|H^{S}\right|+\left[\frac{(1-v)\left(1-b^{S}\right)\left(1+R^{W}\right) s^{S}+(1+\rho)\left(1-s^{S}\right)\left(1+R^{W}\left(b^{S}\right)^{2}\right)}{(1-v)\left(1-b^{S}\right) s^{S}+(1+\rho)\left(1-s^{S}\right)}\right] T^{S}\left|H^{N}\right|}{\left[\frac{\left(1-s^{N}\right)\left[(1-v)\left(1-\alpha^{N}\right)\left(1-b^{N}\right)+(1+\rho) b^{N}\right]}{(1-v)\left(1-b^{N}\right) s^{N}+(1+\rho)\left(1-s^{N}\right)}\right] T_{11}^{N}\left|H^{S}\right|+\left[\frac{\left(1-s^{S}\right)\left[(1-\nu)\left(1-\alpha^{S}\right)\left(1-b^{S}\right)+(1+\rho) b^{S}\right]}{(1-v)\left(1-b^{S}\right) s^{S}+(1+\rho)\left(1-s^{S}\right)}\right] T_{11}^{S}\left|H^{N}\right|} .
$$

When $b^{N}<\bar{b}^{N}$ and $b^{S}<\bar{b}^{S}$, with $\bar{b}^{N}=-\left(1-\alpha^{N}\right)(1-v) /\left(v+\rho+(1-v) \alpha^{N}\right)$ and $\bar{b}^{S}=$ $-\left(1-\alpha^{S}\right)(1-v) /\left(v+\rho+(1-v) \alpha^{S}\right)$, we get $\mathscr{T}_{\infty}^{W}<0$. Since $\mathscr{T}_{\infty}^{W}<0$ when $b^{N}<\bar{b}^{N}$ and $b^{S}<\bar{b}^{S}$, it follows that $\mathscr{P}_{\infty}^{W}(1)>0$. Applying Lemma 5 and Lemma 6 to (39), we then obtain

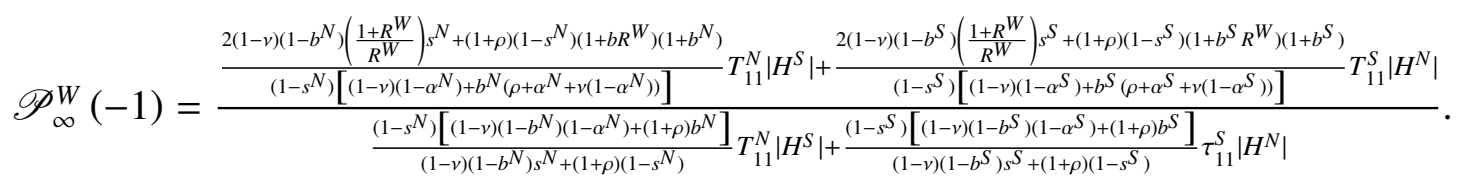

Under $b^{N}<\bar{b}^{N}$ and $b^{S}<\bar{b}^{S}$, we derive that $\mathscr{P}_{\infty}^{W}(-1)<0$ since $\bar{b}^{N}<-1 / R^{W}<-1$ and $\bar{b}^{S}<-1 / R^{W}<-1$. As a result, the starting point is in the left area outside the triangle $\mathscr{A} \mathscr{B} \mathscr{C}$. Let us now consider the end point $\left(\mathscr{T}_{1}^{W}, \mathscr{D}_{1}^{W}\right)$. To determine the precise location of the end point $\left(\mathscr{T}_{1}^{W}, \mathscr{D}_{1}^{W}\right)$, it is sufficient to determine whether $\Delta^{W}\left(\mathscr{T}^{W}\right)$ is pointing upward or downward. $\Delta^{W}\left(\mathscr{T}^{W}\right)$ is pointing upward or downward depending on the sign of $\mathscr{D}^{W^{\prime}}(\gamma)$. It follows from Lemma 5, Lemma 6 and (38) that $\mathscr{D}^{W^{\prime}}(\gamma)$ is given by

$$
\mathscr{D}^{W^{\prime}}(\gamma)=-\frac{R^{W}\left[\frac{\left(1-s^{N}\right)(1+\rho)\left(1-\alpha^{N}+\alpha^{N} b^{N}\right)}{(1-\nu)\left(1-b^{N}\right) s^{N}+(1+\rho)\left(1-s^{N}\right)} T_{11}^{N}\left|H^{S}\right|+\frac{\left(1-s^{S}\right)(1+\rho)\left(1-\alpha^{S}+\alpha^{S} b^{S}\right)}{(1-\gamma)\left(1-b^{S}\right) s^{S}+(1+\rho)\left(1-s^{S}\right)} T_{11}^{S}\left|H^{N}\right|\right]}{\left(\alpha^{N} \Phi^{N}+\alpha^{S} \Phi^{S}\right)(\gamma-1)^{2}\left[\frac{\left(1-s^{N}\right)\left[(1-v)\left(1-b^{N}\right)\left(1-\alpha^{N}\right)+(1+\rho) b^{N}\right]}{(1-\gamma)\left(1-b^{N}\right) s^{N}+(1+\rho)\left(1-s^{N}\right)} T_{11}^{N}\left|H^{S}\right|+\frac{\left(1-s^{S}\right)\left[(1-\nu)\left(1-b^{S}\right)\left(1-\alpha^{S}\right)+(1+\rho) b^{S}\right]}{(1-v)\left(1-b^{S}\right) s^{S}+(1+\rho)\left(1-s^{S}\right)} T_{11}^{S}\left|H^{N}\right|\right]} .
$$


Under $b^{N} \in\left(\underline{b}^{N}, \bar{b}^{N}\right)$ and $b^{S} \in\left(\underline{b}^{S}, \bar{b}^{S}\right)$, with $\underline{b}^{N}=-\left(1-\alpha^{N}\right) / \alpha^{N}$ and $\underline{b}^{S}=-\left(1-\alpha^{S}\right) / \alpha^{S}$, we get $\mathscr{D}^{W^{\prime}}(\gamma)>0$ and thus $\Delta^{W}\left(\mathscr{T}^{W}\right)$ is pointing downward. Therefore when $b^{N} \in\left(\underline{b}^{N}, \bar{b}^{N}\right)$ and $b^{S} \in\left(\underline{b}^{S}, \bar{b}^{S}\right)$, the only possibility to get local indeterminacy is that $\Delta^{W}\left(\mathscr{T}^{W}\right)$ crosses the interior of the segment $\mathscr{A} \mathscr{C}$. This requires that $\mathscr{T}^{W}>0$ when $\mathscr{D}^{W}=-1$. From (38), by solving $\mathscr{D}^{W}=-1$ and by using Lemma 5 and Lemma 6 , one has

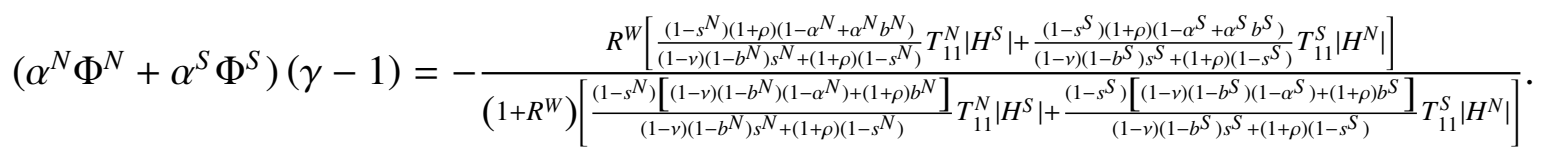

which holds if $b^{N} \in\left(\underline{b}^{N}, \bar{b}^{N}\right)$ and $b^{S} \in\left(\underline{b}^{S}, \bar{b}^{S}\right)$. Substituting $\mathscr{D}^{W}=-1$ in $\mathscr{T}^{W}$, defined in (37). We get that $\mathscr{T}^{W}>0$ when $\mathscr{D}^{W}=-1$ if $\alpha^{N} \in\left(\underline{\alpha}^{N}, 1 / 2\right), \alpha^{S} \in\left(\underline{\alpha}^{S}, 1 / 2\right), s^{N} \in(1 / 3,1 / 2)$, $s^{S} \in(1 / 3,1 / 2), b^{N} \in\left(\underline{b}^{N}, \bar{b}^{N}\right), b^{S} \in\left(\underline{b}^{S}, \bar{b}^{S}\right)$ and $\varepsilon_{r k}^{W}>\underline{\varepsilon}_{r k}^{W}$. The bound $\underline{\varepsilon}_{r k}^{W}$ is defined as

$$
\underline{\varepsilon}_{r k}^{W}=\frac{\left(1+R^{W}\right) \tau_{11}}{\frac{T_{11}^{N}}{s^{N}} \mathscr{X}_{N}\left|H^{S}\right|+\frac{11}{s^{S}} \mathscr{X}_{S}\left|H^{N}\right|}
$$

with:

$$
\begin{aligned}
& \mathscr{X}_{N}=(1+\rho)\left[R^{W}\left(1-s^{N}\right)\left(1-b^{N}\right)+b^{N} s^{N}\left(1+R^{W}\right)\right]+(v-1) s^{N}\left(\frac{1+R^{W}}{R^{W}}\right)+ \\
& \frac{\tau_{31}\left(2-\alpha^{N}-\alpha^{S}\right) R^{W}\left[(v-1)\left(1-b^{N}\right)\left(1-R^{W}\right) s^{N}-(1+\rho)\left(1-s^{N}\right)\left(1-R^{W}\left(b^{N}\right)\right)\right]}{\tau_{21} K^{W *}\left(1-b^{N}\right)}, \\
& \mathscr{X}_{S}=(1+\rho)\left[R^{W}\left(1-s^{S}\right)\left(1-b^{S}\right)+b^{S} s^{S}\left(1+R^{W}\right)\right]+(v-1) s^{S}\left(\frac{1+R^{W}}{R^{W}}\right)+ \\
& \frac{\tau_{31}\left(2-\alpha^{N}-\alpha^{S}\right) R^{W}\left[(v-1)\left(1-b^{S}\right)\left(1-R^{W}\right) s^{S}-(1+\rho)\left(1-s^{S}\right)\left(1-R^{W}\left(b^{S}\right)\right)\right]}{\tau_{21} K^{W *}\left(1-b^{S}\right)},
\end{aligned}
$$

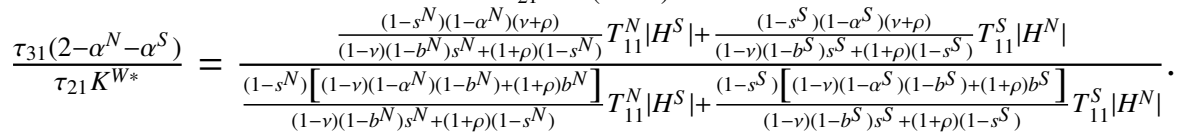

The bifurcation values $\gamma^{W, \mathcal{T}}$ and $\gamma^{W, \mathcal{F}}$ are respectively defined as the solutions of $\mathscr{P}^{W}(1)=$ $1-\mathscr{T}^{W}+\mathscr{D}^{W}=0$ and $\mathscr{P}^{W}(-1)=1+\mathscr{T}^{W}+\mathscr{D}^{W}=0$, and given by

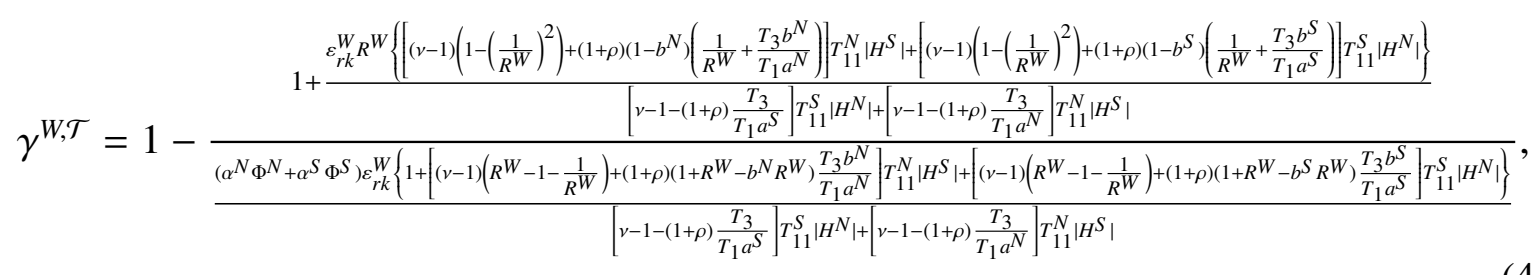

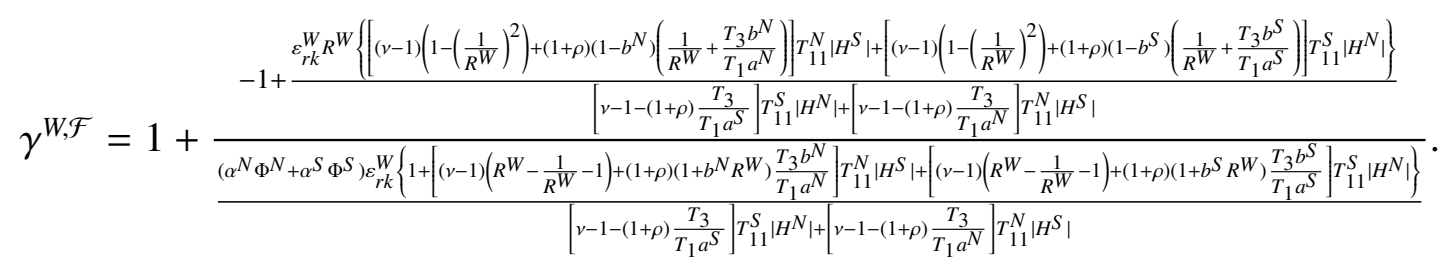

Results follow. 


\section{References}

Aloi, M., and T. Lloyd-Braga (2010), "National labor markets, international factor mobility and macroeconomic instability", Economic Theory 43, 431-456.

Aloi, M., Huw D. Dixon, and T. Lloyd-Braga (2000), "Endogenous fluctuations in an open economy with increasing returns to scale", Journal of Economic Dynamis $\mathcal{F}$ Control 24, 97-125.

Bajona, C., and T. Kehoe (2008), "Demographics in dynamic Heckscher-Ohlin models: overlapping generations versus infinitely-lived consumers", Federal Reserve Bank of Minneapolis Staff Report 377.

Benhabib, J., and K. Nishimura (1998), "Indeterminacy and sunspots with constant returns", Journal of Economic Theory 81, 58-96.

Cecchi, D., and C. Garcia-Peñalosa (2010), "Labour market institutions and the personal distribution of income in the OECD", Economica 77, 413-450.

di Giovanni, J., and A. Levchenko (2009), "Trade openness and volatility", Review of Economics and Statistics 9, 558-585.

Drugeon, J.-P., C. Nourry, and A. Venditti (2010), "On efficiency and local uniqueness in twosector OLG economies", Mathematical Social Sciences 59, 120-144.

Grandmont, J.-M., P. Pintus, and R. de Vilder (1998), "Capital-labor substitution and competitive nonlinear endogenous business cycles", Journal of Economic Theory 80, 14-59.

$\mathrm{Hu}$, Y., and K. Mino (2013), "Trade structure and belief-driven fluctuations in a global economy", Journal of International Economics 90, 414-424.

Iwasa, K., and K. Nishimura (2014), "Dynamic two-country Heckscher-Ohlin model with externality", International Journal of Economic Theory 10, 53-74.

Kose, A., E. Prasad, and M. Terrones (2003), "Financial integration and macroeconomic volatility", IMF Staff Papers 50, 119-141.

Mountford, A. (1998), "Trade, convergence and overtaking", Journal of International Economics 46, 167-182.

Nishimura, K., and K. Shimomura (2002), "Trade and indeterminacy in a dynamic general equilibrium model", Journal of Economic Theory 105, 244-260.

Nishimura, K., and M. Yano (1993), "Interlinkage in the endogenous real business cycles of international economies", Economic Theory 3, 151-168. 
Nishimura, K, A. Venditti, and M. Yano (2010), "Expectation-driven fluctuations and welfare loss under free trade in two-country models", International Journal of Economic Theory 6 , 97-125.

Nishimura, K., A., Venditti and M. Yano (2014), "Destabilization effect of international trade in a perfect-foresight dynamic general equilibrium model", Economic Theory 55, 357-392.

Nourry, C., and A. Venditti, (2011), "Local indeterminacy under dynamic efficiency in a twosector overlapping generations economy", Journal of Mathematical Economics 47, 164-169.

Reichlin, P. (1986), "Equilibrium cycles in overlapping generations economy with production", Journal of Economic Theory 40, 89-102.

Ruelle, D. (1989), "Elements of Differentiable Dynamics and Bifurcation Theory", San Diego: Academic Press.

Shell, K. (1977), "Monnaie et allocation intertemporelle", mimeo, Centre National de la Recherche Scientifique, Paris.

Sim, N., and K.-W. Ho (2007), "Autarky indeterminacy and trade determinacy", International Journal of Economic Theory 3, 151-168.

Takahashi, H., K. Mashiyama, and R. Sakagami (2012), "Does the capital intensity matter? Evidence from the postwar japanese economy and other OECD countries", Macroeconomic Dynamics 16, 103-116.

Woodford, M. (1986), "Stationary sunspot equilibria. The case of small fluctuations around a deterministic steady state", Mimeo, University of Chicago and New York University. 